\title{
Development and application of a preliminary design methodology for modern low emissions aero combustors (Accepted manuscript)
}

\author{
Yize Liu*, Xiaoxiao Sun*, Vishal Sethi *, Yi-Guang Li*, Devaiah Nalianda*, \\ David Abbott*, Pierre Gauthier*, Bairong Xiao **, Lu Wang ** \\ * Centre for Propulsion Engineering, Cranfield University, Bedfordshire MK43 0AL, UK \\ ** AECC Hunan Aviation Powerplant Research Institute, Zhuzhou, Hunan, China \\ Correspondence email: yizeliu.liu@cranfield.ac.uk
}

\begin{abstract}
In this paper, a preliminary design framework containing a detailed design methodology is developed for modern low emissions aero combustors. The inter-related design elements involving flow distribution, combustor sizing, heat transfer and cooling, emission and performance are coupled in the design process. The physics-based and numerical methods are provided in detail, in addition to empirical or semi-empirical methods. Feasibility assessment on the developed work is presented via case studies. The proposed combustor sizing methodology produces feasible combustor dimensions against the public-domain low emissions combustors. The results produced by the physics-based method show a reasonable agreement with experimental data to represent NOx emissions at key engine power conditions. The developed emission prediction method shows the potential to assess current and future technologies. A two-dimensional global prediction on liner wall temperature distribution for different cooling systems is reasonably captured by the developed Finite Difference Method FDM. It can be of use in the rapid identification of design solutions and initiating the optimisation of the design variables. The altitude relight efficiency predicted shows that the method could be used to provide an indicative assessment of combustor altitude relight capability at the preliminary design phase.

The methodology is applied and shows that it enables the automatic design process for the development of a conceptual lean staged low emissions combustor. The design evaluation is then performed. A sensitivity analysis is carried out to assess the design uncertainties. The optimisation of the air distribution and cooling geometrical parameters addresses the trade-off between the NOx emissions and liner wall cooling, which demonstrates that the developed work has potential to identify and solve the design challenges at the early stages of the design process.
\end{abstract}

Keywords: Preliminary design, Low emissions combustors, Aero-engine, Performance, Optimisation 


\section{Nomenclature}

A

AEC Angled Effusion Cooling

$A R \quad$ Area Ratio

$B R \quad$ Bypass Ratio

$C p \quad$ Specific heat capacity

$C_{1} \quad$ Internal convection

$C_{2} \quad$ External convection

$D \quad$ Diameter (m)

$D A C \quad$ Double Annular Combustor

EI Emission Index (g/kg of fuel)

$f \quad$ Fraction

FDM Finite Difference Method

FN Flow Number

$H \quad$ Height (m)

$K \quad$ Conductivity

LTO Landing Take-off

$L W \quad$ Length to Width Ratio

$M a \quad$ Mach Number

$M F \quad$ Mass flow function

NOx Nitrogen Oxides

$O P R \quad$ Overall Pressure Ratio

$P \quad$ Pressure (Pa)

PaSR Partially Stirred Reactor

$P R \quad$ Pressure ratio

$P S R \quad$ Perfectly Stirred Reactor

RTDF Radial Temperature Distribution Factor

$R Q L \quad$ Rich-burn, Quick-quench, Lean-burn

$S \quad$ Mixing parameter

SAC Single Annular Combustor

SN Swirl Number

$T \quad$ Total temperature (K)

Tst $\quad$ Specific Thrust (Ns/kg)

TAPS Twin Annular Premixing Swirler

UHC Unburned Hydrocarbons

V

W

X

$\Lambda$

$\Psi$

$\eta$

$\tau$

$\rho$

$\varepsilon_{g}$

$\sigma$

$\phi$

$\epsilon$

Velocity $(\mathrm{m} / \mathrm{s})$

Mass flow (kg/s)

Variable

Loading Parameter

Flow function

Combustion efficiency (\%)

Residence time (ms)

Density $\left(\mathrm{kg} / \mathrm{m}^{3}\right)$

Emissivity of gas

Deviation

Equivalence ratio

Residual 


\section{Introduction}

Pollutant emissions from aircraft in the vicinity of airports and at altitude are of great public concern due to their impact on the environment and human health. The legislation aimed at limiting aircraft emissions has become more stringent over the past few decades. This has resulted in an urgent need to develop low emissions combustors to meet legislative requirements and reduce the impact of civil aviation on the environment. [1] Design of a low emissions combustor is a challenging task as it demands knowledge of complex threedimensional flow, liquid droplet evaporation, chemical kinetics, heat and mass transfer, etc. The research mainly focuses on the experimental and numerical study to investigate the detailed physics in the combustion chamber with very limited study in the public domain focusing on preliminary design framework development. The high cost of rig testing and increased complexity of numerical simulations limit their use in the conceptualisation of design. Preliminary design tools are of great importance as they enable novel design solutions to be explored in a relatively shorter timeframe.

Such design tools have been developed by some of the engine OEMs to assist the combustor development. [2][3] However, there are limited design approaches in the public domain. Stuttaford and Rubini developed a preliminary design tool using a network approach. [4] The approach was used to model the combustor mass flow splits and pressure drop using a pressurecorrection methodology. It is also capable of modelling heat loss using conjugate heat transfer models. The detailed combustor design and sizing procedures were however not extensively investigated. Mohammad and Jeng developed a design tool for single annular combustors SAC.[5] The design and combustor sizing procedures are empirical/semi-empirical based. Khandelwal et al. conducted the design and performance analysis for staged combustors. [6] The methodology developed follows the conventional method similar to Mohammad and Jeng's approach. More recently, Mark and Selwyn performed design and analysis on a low bypass turbofan combustor.[7] The dimensions of the designed combustor were determined based on the empirical formulas. Li et al. developed design methods for lean direct injection combustors.[8] The work mainly focused on aerodynamic design. Roshan et al. provided design philosophy for a laboratory-scale combustor where various empirical relations were adopted in the design process. [9]

The contributions of the present research compared to the previous studies are: 1) A more detailed and compressive design approach for modern low emissions combustors is developed. In particular, the methods for determining air and fuel distribution for staged combustors, fuelair mixer, cooling system, and other key combustor components are provided in details. 2) Previous approaches focus specifically on certain design elements and design procedures are applied sequentially in the design process. Interactions of different design elements in the preliminary design phase are not extensively studied. In current work, the inter-related design elements involving aerodynamic sizing, heat transfer and cooling, emission and performance are coupled in the design process. 3) The previous studies are generally related to conventional design rules and mainly empirical-based. In this study, multiple approaches including physicsbased and numerical methods are provided in detail, in addition to empirical/semi-empirical methods. 4) Limited studies combine preliminary design with optimisation to investigate the 
trade-offs between conflicting performance requirements, this will be considered in the current design framework.

Methodology development is presented in section 2. Section 2.1 provides an overview of the whole design framework. The coupled design elements and their interactions are presented in 2.2. Section 2.3-2.7 show detailed methods. It comprises flow distribution, combustor sizing, emission prediction, heat transfer and cooling, and performance analysis. The developed flow distribution programme produces air and fuel data into different combustor sections. The combustor sizing results in the combustor casing, liner, diffuser, fuel-air mixer, and cooling system design. The proposed heat transfer and cooling methodology estimates the airflow required for the liner cooling. It is also capable of providing a two-dimensional temperature distribution along the liner wall. The developed emission methodology provides an assessment of key engine emission index (i.e., $\mathrm{NO}_{\mathrm{x}}$ ) for different combustor technologies at key engine power conditions. For performance evaluation, the combustion efficiency levels are assessed. In section 3, the feasibility assessment on each design approach is presented via case studies. An overview of each design approach is provided. The developed methodology is then applied and presented in section 4. A conceptual lean staged combustor is designed for a smaller turbofan engine. The overall performance of the designed combustor is predicted. In section 5, a multi-objective optimisation is incorporated in the design framework. The work focuses on optimising airflow distribution and cooling geometrical parameters to addresses the trade-off between the NOx emissions and liner wall cooling.

\section{Methodology development}

\subsection{Methodology overview}

The global design process within the developed framework comprises a series of steps as indicated in Fig.1. Before starting the process, various design parameters are defined. As listed in Table 1, the design parameters include: 1) aerothermal parameters (i.e., combustor inlet/outlet pressure $P_{3,4}$, temperature $T_{3,4}$, air and fuel mass flow $W$ ) that defined by the engine cycle and performance calculations at different engine operating conditions. 2) Combustor inlet and outlet pitch locations and flow areas determined by the compressor and turbine design. For the development of a modern combustor, the design aims to meet certain requirements. Therefore, the performance parameters, namely the design target values are specified. Although emissions could be a major focus when designing a low emissions combustor, the importance of high combustion efficiency, low-pressure loss $\Delta \mathrm{P}$, lower liner temperature, and high altitude relight capability should be explored thoroughly. The definition of combustor architecture (e.g. single or double annular, axial/radial/internally staged combustor, etc.) is also required. Also, the geometric constraints, namely the limitations on the design space should be given. This is defined by the customer requirement based on previous design experiences.

After initialisation, the process starts with flow distributions. The airflows through different combustor sections are initially estimated. Specifically, the air mass flows through combustor swirlers, different stages, dome, passage, and liner cooling flow are calculated. If staged combustors are designed, it allows the fuel schedule between the pilot and the main stage. With calculated air and fuel data, the combustor zonal fuel-air stoichiometric ratios can be defined. 
Then, the design parameters and calculated flow data are transferred to the combustor sizing algorithm. A new combustion system design relies heavily on past experiences. It is still governed by correlations which could be very useful for combustor sizing. [10] Within the current sizing algorithm, the design variables are defined, and various sizing rules and semiempirical correlations are incorporated. In particular, the detailed and new design rules were developed to determine the geometries of liner, diffuser, fuel-air mixer and cooling holes. Moreover, the algorithm also allows the customised semi-correlations to be incorporated into the framework to assist the designers according to their personal needs.

The defined aerothermal, flow distribution and combustor geometric data are then transferred to the developed emissions, heat transfer and performance algorithms where evaluation on the designed combustor is performed. For emission analysis, NOx is of high importance for the design of future aero-engine combustors since the legislative requirement becomes increasingly stringent. [1] The empirical correlations limit their use for the emission prediction since the coefficients in the parameters may not be valid for new combustors. Although higherorder numerical simulations would provide more accurate prediction, the calculations are not efficient for technology evaluations, particularly in the preliminary design phase. In the present work, the physics-based method is developed within the emission algorithm. The combustion chamber is divided into a number of zones based on the layout of the combustor and each zone is modelled as a combination of several stirred reactors. The approach reduces dependence on specific rig test information, and the modularity and extensibility enable the new technology to be evaluated rapidly. The method details are provided in section 2.5. One-dimensional heat transfer analysis is usually performed to evaluate liner mean temperatures and estimate the cooling flow. However, the liner temperature distribution is of more interest because peak temperatures and temperature gradient are two crucial factors that affect liner integrity. The multi-dimensional analysis is considered in the current algorithm by approximating the liner temperature distribution using the Finite Difference Method. Section 2.6 provides the details. Safety is always the most important airworthiness criterion and there is no exception for low emissions combustors design. High combustion efficiency not only at design point but during altitude relight is required. A semi-empirical approach is proposed in the performance algorithm to evaluate altitude relight efficiency. The algorithms are interrelated, and a detailed description of the coupling process is presented in section 2.2.

The iterative design loop is then formed by changing the combustor geometric design variables and air/fuel data and checking whether the designed combustor meets the design targets. The iteration will continue until the design meets all the requirements. The process is experiencedriven and is trial and error. A more effective way to attain the design goals is by using the optimisation technique to automate the design process. In this work, a genetic algorithm optimiser is also connected to the design framework. It is achieved by optimising the design variables to address the combustor trade-offs between the multi-design objectives. 


\subsection{Design element interaction}

Instead of applying a sequential design procedure, the developed algorithms are coupled to enable a mutual communication process when conducting a design task. This allows the designers to rapidly explore the mutual impact relation between different design elements. Table 2 summarises the interactions by listing the parameters where each algorithm receives from and transfer to other algorithms. For each algorithm, the directly coupled algorithms are also given.

- Flow distribution

The combustor inlet aerothermal parameters (Table1.) are initially received by the algorithm. Within the algorithm, the air mass flow used for combustion and liner cooling is estimated. Meanwhile, the airflow through the different combustor sections components is determined. The fuel splits between the pilot and the main stage are also defined if a staged combustor is designed. The calculated air and fuel flow data are transferred to: 1) combustor sizing algorithm, the dimensions of swirlers, combustor cooling holes and liner zone (e.g. the pilot and main zone, dome and passage) can be defined with given air mass. The fuel flow is used to provide the fuel nozzle orifice dimensions. 2) Heat transfer and cooling algorithm; the initially estimated cooling flow will be used for liner heat transfer and temperature analysis. 3) Emission. The fuel and air-mass, and the zonal fuel-air stoichiometry are transferred to the reactors in the emission algorithm. Within reactors, the reactant mixture quantity is defined. 4) Optimisation, the resulting flow parameters can be defined as variables to the combustor flow optimisation. Although the algorithm does not directly link with performance algorithm (i.e., combustion efficiency is evaluated based on the inlet parameters), the resulting liner dimensions based on flow distribution will be used for efficiency analysis.

- Combustor sizing

The sizing program receives the design parameters (Table 1.) and mass flow data from the flow distribution algorithm. Within the program, the dimensions of the combustion chamber and combustor components are generated. The determined geometrical values are coupled to: 1) Heat transfer and cooling algorithm. Specifically, the liner cooling geometrical data provide the computational domain where the grids are generated for FDM analysis. 2) Emission. The produced overall and zonal chamber dimensions define the geometric boundary conditions for each reactor; in specific, the inlet and outlet areas, and reactor length. The defined reactors are then further connected to formulate the network. 3) Performance. Since the semi-empirical approach is used to evaluate combustion efficiency levels, the calculated chamber dimension is an important parameter. 4) Optimisation. The identified geometrical design variables could be treated as ones used for multi-disciplinary optimisation.

\section{- Emission}

The mass flow calculated from flow distribution model, and geometric parameters from combustor sizing model provide the basis for emission modelling. Within the algorithm, the chemical kinetics calculations inside the stirred reactors are executed. The resulting parameters are subsequently transferred to 1) Heat transfer and cooling. Typically, the zonal gas temperature and radiation, convection (i.e., radiation term $\mathrm{R} 1$ and convection term $\mathrm{C} 1$ ) will be used to evaluate liner heat transfer. 2) Optimisation, the emission index is regarded as one of the objective functions when minimisation of $\mathrm{NO}_{\mathrm{x}}$ emission is a primary task for modern low 
emission gas turbines. Despite there is no direct data communication to performance algorithm, the reduction of thermal NOx requires lower flow residence time in the reactors and hence the reduced chamber dimension, which in turn affects combustion efficiencies. In this way, the performance algorithm is indirectly coupled.

- Heat transfer and cooling

The model receives liner geometrical values from the combustor sizing algorithm, and zonal gas temperature and radiation from the emission algorithm. Since it interacts with sizing model, the liner geometric data are updated after iterations to meet the liner temperature requirement. Therefore, the new generated liner geometry will be transferred back to the sizing algorithm. In addition, the produced liner temperature data are used as the objective function when minimisation of liner peak temperature is a design task for enhancing liner integrity. Although the model is not directly interacted to performance model through direct data communications, the resulting liner dimensions based on the performance criteria would change the liner geometry, in which the coolant mass per unit area is amended and hence affects cooling effectiveness.

- Performance

The combustion efficiencies are assessed using the engine and combustor inlet parameters, and the geometrical data from the combustor sizing. The resulting efficiency levels can be treated as one of the important objectives for optimisation. As describes before, although it is indirectly linked to the rest algorithms, the mutual impact relations exist.

- Optimisation

The design input parameters are considered as input to the optimisation problem. The objectives are defined based on the design requirement. In this case, the combustor emission, liner temperature, and performance can be regarded as multi objectives in the optimisation problem. Potentially, all the design variables in the flow distribution and sizing algorithms could be treated as optimising variables, except the fixed design parameters (i.e., combustor inlet/outlet aerothermal and geometric parameters/constraints). In the present study, some key parameters are identified and selected as variables through sensitivity studies. The constraints are then defined. The optimisation method is based on a genetic algorithm and the multiobjective optimisation and trade-off analysis are performed. The generated Pareto solutions will be produced. Thus, all the developed algorithms can be coupled to the optimiser.

\subsection{Flow distribution}

Mellor [11] and Mattingly [12] developed air distribution procedures that are applied to conventional and rich-burn combustors design. For modern fuel staged combustors, fuel distribution is also required, and the procedure is limited in the open literature. In the present work, a design process is established to allow air and fuel distributions are simultaneously obtained. Table 3 summaries the design parameters, variables, and criteria. The procedure starts with the estimation of dome equivalence ratio $\phi_{d}$ at the design point as a design variable. In contrast to conventional combustors, the air used for combustion enters through the combustor dome only. Thus, the total combustor airflow is initially divided into dome and passage air. The dome air is mainly used for the combustion process and the passage flow is for liner cooling. Thus, the emission and liner temperature are the main checking criteria at the design 
point. Evaluation of emission and liner temperature can be initiated once the combustor sizing is performed. For the fuel split process, the air $\left(\mu_{a_{-} p}, \mu_{a_{-} m}\right)$ and fuel fractions $\left(\mu_{f_{-} p}, \mu_{f_{-} m}\right)$ at each stage are the design variables. The air and fuel mass, and the resulting fuel-air stoichiometry at each stage are then defined. Then, the design criteria are 1) pilot $\phi_{p_{-} d p}$ and main $\phi_{m_{-} d p}$ at design point and 2) pilot $\phi_{p_{-} i d l e}$ at idle. The former is to ensure both combustor zones operate at a similar level; the latter is to maintain a sufficient pilot equivalence ratio (close to stoichiometric value) to address the low power stability issues. At each stage, the airflow can be further divided into swirling air and dome cooling air.

\subsection{Combustor sizing}

\section{- Combustion Chamber}

The empirical-based approaches are extensively adopted to evaluate the casing and liner dimensions. [5][7][11] However, the chamber packing (i.e. the process to accommodate the geometric boundary constraints) was not explicitly studied. The current calculation enables the automatic sizing process to facilitate the chamber packing, in addition to meet other design requirements. The design parameters, variables, and criteria are listed in Table4.

The chamber calculations receive design parameters (Table 1.) and flow data as the input parameters. The dome and passage flow Mach numbers $\left(M a_{d}, M a_{p}\right)$ are initially identified as design variables. Then, the dome and passage area can be defined using the flow function (Eq.1) The casing area is the summation of dome and passage areas. Next, the combustor reference pitch radius $R_{\text {pit }}$, is another design variable. For annular combustors, the casing, dome and passage heights can be estimated using the geometric relation defined in Eq. 2

The resulting chamber height is required to accommodate the provided design space. Therefore, the geometrical constraint is a design criterion. The next task is determining the chamber volume. The zonal and total volume is defined using the loading parameter (Eq.3 [21]). Combustion efficiency is the design criterion to freeze the chamber volume, the efficiency level has to be satisfied at different engine powers, especially during engine altitude relight. Then the zonal and total chamber length can be subsequently calculated with the defined height and volume. The downstream zone pitch radius $R_{p i t} d z$ is another design variable, which is iterated to produce the same liner inclined angle as a design criterion. The resulting liner length is further checked to meet the geometrical requirement. Finally, the design variables are iterated until all design criteria are met. The casing and chamber geometrical values (Table $\mathrm{x}$ ) are generated as the design outcomes.

$$
\begin{gathered}
\Psi=\frac{W \sqrt{T}}{P A} \\
A=2 \pi R_{\text {pit }} H \\
\Lambda=\frac{W_{3}}{\operatorname{VOL} P_{3}{ }^{a} 10^{b\left(T_{3}-c\right)}}
\end{gathered}
$$

$W_{3}, P_{3}, T_{3}$ are combustor inlet parameters, $V O L$ is the combustor zonal or total volume, $a, b, c$ are the pressure and temperature dependent exponents that derived experimentally. 


\section{- Diffuser}

Mohammad [5] and Khandelwal [6] developed and applied the procedure for computing prediffuser dimension based on minimum pressure loss criteria. In the present study, the combination of faired and dump diffuser sizing process is considered. The task (Fig.5) begins with the area ratio AR as the design variable to control the flow Mach number of the diffusion flow. If the AR cannot be achieved by faired diffuser due to space constraints and excessive friction loss, then a combination type is chosen. The additional dump diffuser produces a stable flow pattern insensitive to manufacturing tolerances and variation in the inlet velocity profile. For designing the faired diffuser, with the initially estimated AR, the length to height ratio, $\mathrm{LH}$, diffusion angle can be evaluated. The diffuser performance chart may be of help to define these dimensions. [11] The maximum permitted length to height ratio, and maximum diffusion angle $\theta$ are checked (e.g. LH $<6$ [12], $\theta<8$ [11]) to ensure the design produces feasible dimensions. Then, pressure recovery coefficients are used to evaluate diffuser pressure losses. [12] The pressure loss is a design criterion to ensure the cold loss due to the diffuser is minimised. If a combined type is used, flow function (Eq.1) is used to calculate the required outlet area $A_{32}$ for the desired flow Mach number, which is also a design criterion. Iteration of the ideal pressure recovery coefficient is required to obtain the right flow function and produce the required diffuser outlet section. Finally, the dump gap $D_{d}$ is estimated.

\section{Fuel-air mixer}

The fuel-air mixer is a critical component comprising fuel atomiser and air swirlers. In the preliminary design studies, there are limited procedures to detail the design. This results in a need for the current study to propose a design process. The design receives the fuel and swirling flow aerothermal parameters, and dome geometry as the main inputs.

It starts with the number of injectors. Eq.4 is used with the number rounded to the nearest even integer. Pressure atomisers are widely adopted due to better combustion stability and operability at lower powers. For designing an atomiser, the orifice diameter $D_{o}$ is a design variable. Then the nozzle area and discharge coefficient $C_{D}$ can be derived. With the known $C_{D}$ , the non-dimensional geometrical group, which can be used as another design variable (eq.5 [32]) to determine the swirl chamber dimensions. Once the geometry is available, the spray cone angle $\theta_{-} s$ and saunter mean diameter SMD, as two design criteria, can be evaluated. Iterations of nozzle orifice and chamber non-dimensional parameters are performed until the desired $\theta_{-} s$ and SMD are generated. The mixing chamber dimension is also calculated if premixed combustion is used. The chamber dimensions are defined based on ignition delay (Eq. 6 [13]) design criterion in which the flow residence time does not exceed the value and hence controls the risk of auto-ignition.

Modern mixers utilise the air swirlers in conjunction with pressure atomiser to achieve fuel atomisation in air blast mode. The swirler design process starts with a selection of vane types (flat or curved vane) and vane angles, as design variables. The swirler area is then computed based on pressure drop and swirling flow. The tip diameter can be then evaluated with the known swirler area and hub dimension. The next step involves defining the vane numbers, spacing, and chord length that then be known based on spacing to chord ratio. Since the chord length and the angle are known, the width of the swirler is therefore determined. The vane 
thickness should consider the manufacturing limit. Geometry constraint is a design criterion, which requires the calculated swirler dimension to fit in the combustor dome. The second design criterion is the swirl number SN (Eq. (7)) which requires the swirlers to produce the expected swirling strength. Finally, the iteration of the vane type and angle can be then performed until it satisfies the criteria. The process is similar if multi-staged swirlers are considered.

$$
n=2 \pi R_{\text {pit }} / H_{d}
$$

$R_{\text {pit }}$ is reference pitch radius. $H_{d}$ is dome height.

$$
C_{D}=0.0616 \frac{D_{s}}{D_{0}} \frac{A_{P}}{D_{S} D_{o}}
$$

$D_{s}, D_{0}$ are swirl and orifice diameter. $A_{P}$, Fuel inlet port area

$$
\tau=0.508 e^{(3377 / T)} P^{-0.9}
$$

$P, T$ are the inlet pressure and temperature.

$$
S N=\frac{2}{3} \frac{1-\left(D_{h u b} / D_{S w}\right)^{3}}{1-\left(D_{h u b} / D_{S w}\right)^{2}} \tan \theta
$$

$D_{h u b}, D_{s w}$ are swirler hub and tip diameters. $\theta$ is vane angle.

- Cooling system

Advanced cooling technology is demanding for low emissions combustors. This includes jet impingement, effusion or angled effusion cooling (AEC), double-wall arrangement, which are widely adopted in modern combustors. Most of the work focuses on conventional film cooling. This results in an effort in the present study to conceive a preliminary sizing procedure for the new cooling systems. The design receives the coolant mass and heat transfer data as the main input. The procedure for designing an effusion-impingement system is performed initially at the mean radius of the liner. It starts with the number of cooling rows $N_{c r}$ as a design variable. The coolant mass per row is then estimated. Next, both the effusion and impingement hole diameter can be calculated using Eq.8. Then, the hole spacing $S$ is regarded as another design variable, which further defines the hole numbers in the single row. The typical value is 3-8 times the hole diameter. [15] The manufacturing limit is a design criterion to allow a feasible dimension. In addition, the numbers of the impingement hole, in each row, should remain the same as effusion holes. This is to ensure no cross flow occurs. If an angled effusion hole is designed, the decrease in hole angles leads to improved cooling effectiveness. The resulting liner segmental length should be also checked so that it has a sufficient dimension for impingement cooling. The jet impingement location $X_{D}$ and gap $H_{S}$ between impingement liner and effusion plate are also regarded as the design variables to provide effective liner cooling. In this work, $X_{D}$ and $H_{S}$ are initially assumed to be 0.6 and $0.002 \mathrm{~m}$. Finally, the liner cooling geometric data is then coupled to the heat transfer algorithms. Iteration of the geometric parameter is required to meet the liner temperature requirement.

$$
A_{h}=W_{c} /\left(C_{D} \times \sqrt{2 \times \Delta P \times \rho_{c}}\right)
$$

$W_{c}$ is coolant mass flow, $C_{D}$ is discharge coefficient, $\Delta P$ is pressure drop and $\rho_{c}$ is coolant density. 


\subsection{Chemical pollutants}

The details of the developed emission algorithm using the stirred-reactor approach (Fig.2) are presented as follows:

a) The combustor inlet aerothermal parameters are used as inputs.

b) The air and fuel splits into each combustor region are defined based on the flow distribution calculation in section 2.3

c) The combustor architecture is represented by reactor layouts. These include the definition of different zones that varies from combustor configuration. The dimensions of the zone and reactor are defined based on the combustor sizing algorithm in section 2.4. For reactors in the same zone, the inlet and outlet areas are defined based on the mass flow fraction.

d) The stirred reactor method is developed. Two reactors are implemented: Perfectly Stirred Reactor PSR, and Partially Stirred Reactor PaSR. The main differences between the two are distinguished by their mixing characteristics.

For PSR, it is assumed that the mixing is instantaneous, uniform and ideal inside the reactor. The mixing characteristics are represented by two parameters: mixing fraction $f_{m}$, and residence time (Eq.9)

$$
f_{m}=\frac{W_{f}}{W_{f}+W_{a}} ; \tau=\frac{\bar{\rho} V}{W_{g}}
$$

where $\bar{\rho}$ is the mean density of the gas, $V$ is the volume of the reactor and $\dot{m}$ is the reactor gas mass flow. Thus, the mixing is characterised by the mean value of $f_{m}$, and residence time $\tau$.

For PaSR, it is assumed that the mixing process is complete at a macro level, but not on a molecular scale. Hence, the variations in gas composition $f_{m}$ and residence time $\tau$ are presented. The variation in $f_{m}$ is approximated by Probability Density Function PDF where Clipped Gaussian distribution is initiated. To fully define the probability profile, the deviation $\sigma$ is determined by an empirical mixing parameter $S$. The variation in $\tau$ is dependent on $f_{m}$ variation since the gas composition variation produces density variation.

$$
S=\frac{\sigma}{f_{m}}=0.4515 \phi^{3}-2.6417 \phi^{2}+4.1756 \phi-1.3023
$$

$\phi$ is the mean equivalence ratio

e) Then, the NOx formation rate is predicted. The thermal NOx calculation is based on the Zeldovich mechanism and the contribution of $\mathrm{N}_{2} \mathrm{O}$ to thermal NO formation. Prompt NO can be estimated through a modified version of the global kinetic parameter proposed by De Soete [16][17] (Eq.11) Since Jet-A1 fuel is regarded as a light distillate fuel which does not contain a high level of fuel bounded nitrogen, the contribution of Fuel NO to the NO rate formation is insignificant. Thus, fuel NO is not modelled in this work.

$$
M_{N o x}=\left\{\begin{array}{lr}
\int \frac{2 \bar{M}_{N O}}{\rho}\left(1-\alpha^{2}\right)\left\{\frac{R_{1}}{1+\alpha K_{1}}+\frac{R_{6}}{1+K_{2}}\right\} d t & \left(\text { Thermal } \mathrm{NO}_{\mathrm{x}}\right) \\
\int\left(\frac{\bar{M}_{N O}}{\rho}\right) f_{p r} k_{p r}^{\prime}\left(\left[O_{2}\right]\right)^{a}\left[N_{2}\right]\left[C_{12} H_{23}\right] \exp \left(\frac{-36499.507}{T}\right) d t & \left(\text { Prompt } \mathrm{NO}_{\mathrm{x}}\right)
\end{array}\right.
$$

$d t$ is the residence time within each reactor, $R_{i}$, denotes a 'one-way equilibrium' reaction rate, 
(e. g. $R_{1}=k_{1 f}[N][N O], k_{1 f}$ is the forward reaction coefficient. [N] [NO] are the concentration of species $\mathrm{N}$ and NO. $\left[\mathrm{O}_{2}\right],\left[\mathrm{N}_{2}\right]$ are the concentration of $\mathrm{O}_{2}$ and $\mathrm{N}_{2}, \bar{M}_{\mathrm{NO}}$ is the molar weight of $\mathrm{NO}, \rho$ is the density of inlet flow. For prompt $\mathrm{NO}_{\mathrm{x}}, f_{p r}$ is a correction factor that incorporates the effect of fuel type. $k_{p r}^{\prime}$ is a pressure and temperature dependent coefficient.

f) The kinetics calculation assumes that the Zeldovich mechanism is decoupled from the main combustion process. Thus, the temperature, the concentration of species in Eq.11 can be determined using the local chemical equilibrium values.

g) Once the reactor is formulated for each zone, a network is established to connect each element and enable the chemical reaction taking place along the combustor. In the present study, axial networking is applied to simplify the modeling of the flow field. It could be further refined if detailed knowledge flow mixing characteristics is known.

h) The emission index and other parameters (e.g. temperature and gas density) are obtained as outputs at the exit of the reactor.

\subsection{Heat transfer and cooling}

The procedures (Fig.3) for calculating the heat transfer and liner wall temperatures are presented as follows:

a) The calculation process initially receives $W_{f}, W_{c}, P_{3}, T_{3}$ as input parameters. $W_{f}, P_{3}, T_{3}$ are obtained from engine performance simulation. $W_{c}$ is derived based on the air distribution calculation presented in section 2.3

b) The cooling geometry is determined based on the cooling system design under the sizing algorithm (section 2.4). In particular, the cooling segmental length $L_{c}$, hole diameter $D_{h}$, angle $\theta_{h}$, spacing s, and impingement location are defined.

c) The domain of interest is discretised into nodal points and elements in $\mathrm{x}$ and y directions. For an element on the outer surface of the cooling liner (Fig.9), the central node is symbolled as $(j, k)$. The surrounding left, right and upper nodes are denoted as $(j-1, k),(j+1$, $\mathrm{k}$ ), and ( $\mathrm{j}, \mathrm{k}+1)$, respectively. $\mathrm{J}$ locations indicate the $\mathrm{x}$ increment and $\mathrm{k}$ locations indicate $\mathrm{y}$ increment.

d) The thermodynamic properties calculations include determining the specific heat capacity $C_{p_{-} c}$, heat conductivity $K_{c}$ and viscosity $\mu_{c}$ of the coolant. A curve-fitted polynomial expression is used to evaluate $C_{p_{-} c}:$ [21]

$$
\begin{array}{r}
C_{p_{-} c}=0.992313+0.236688 T_{z}-1.852148 T_{z}{ }^{2}+6.083152 T_{z}{ }^{3}-8.893933 T_{z}{ }^{4} \\
+7.097112 T_{z}{ }^{5}-3.234725 T_{z}{ }^{6}+0.794571 T_{z}{ }^{7}-0.081873 T_{z}{ }^{8}
\end{array}
$$

where $T_{z}=T_{S} / 1000 T_{S}=$ static temperature of the coolant; $C_{p_{-} c}$ is in $\mathrm{kJ} / \mathrm{kg} \mathrm{K}$

$K_{c}$ and $\mu_{c}$ are evaluated based on coolant static temperature $T_{s}$. The gas thermodynamic properties are determined using the NASA CEA algorithm. [18] 
e) The combustor zonal gas temperatures are calculated in the emission algorithm. Eric Goodger's method is used. [19] The approach is capable of determining the gas temperatures for any carbon-hydro non-dissociated mixtures and dissociated mixtures. For dissociated all mixtures at higher temperatures, the degree of dissociation is temperature and pressure dependent. Hence, for all mixtures, the reaction is defined as:

$$
\mathrm{C}_{a} \mathrm{H}_{b}+m\left(\mathrm{O}_{2}+3.76 \mathrm{~N}_{2}\right)=n_{1} \mathrm{CO}_{2}+n_{2} \mathrm{H}_{2} \mathrm{O}+n_{3} \mathrm{CO}+n_{4} \mathrm{H}_{2}+n_{5} \mathrm{O}_{2}+n_{6} \mathrm{~N}_{2}
$$

The solution of the four unknown 'n' values are provided by the molar balance of $\mathrm{C}, \mathrm{H}_{2}, \mathrm{O}_{2}$ and $N_{2}$. The two remaining equations are derived from the equivalent constants at different temperatures:

$$
K_{\mathrm{CO}_{2}}=\frac{n_{1}}{n_{3} \times \sqrt{\frac{p n_{5}}{n_{T}}}} K_{\mathrm{H}_{2} \mathrm{O}}=\frac{n_{2}}{n_{4} \times \sqrt{\frac{p n_{5}}{n_{T}}}}
$$

where $P=$ total pressure of product mixture $n_{T}=$ total moles of the product mixture

Gas temperature is achieved by equating total enthalpy of hot products with formation enthalpy of the fuel (since adiabatic)

$$
\Sigma\left(\Delta H_{f}^{o}+H^{T^{*}}\right)_{P}=\left(\Delta H_{f}^{o}\right)_{\text {fuel }} ; \Sigma\left(H_{t}^{T^{*}}\right)_{P}=\left(\Delta H_{f}^{o}\right)_{\text {fuel }}
$$

where $H_{t}^{T^{*}}=$ total enthalpy $=$ formation $\left(\Delta H_{f}{ }^{o}\right)+$ sensible $\left(H^{T^{*}}\right)$

f) Heat transfer analysis is assumed to be constant around the circumferential direction at any axial location. Fig. 4 shows a section of hot liner a combined impingement and effusion cooling system. Under steady-state conditions, the analysis is restricted to the hot liner wall surface. Based on the governing equation: conservation of energy, for an element with the inside surface $\Delta A_{w 1}$, outside surface $\Delta A_{w 2}$, and effusion hole surface $A_{h s}$, the heat balance becomes:

$$
\left(R_{1}+C_{1}\right) \Delta A_{w 1}-C_{1}{ }^{\prime} A_{h s}=\left(R_{2}+C_{2}{ }^{\prime}\right) \Delta A_{w 2}=K_{1-2} \Delta A_{w 1}
$$

$K_{1-2}$ is the conduction through the liner wall. $R_{1}, R_{2}$ are internal and external radiation and $C_{2}{ }^{\prime}$ is the enhanced convection due to impingement cooling on the outside surface $\Delta A_{w 2}$.

Calculation of internal convection $C_{1}$ requires the knowledge of adiabatic wall temperature that can be derived from the film cooling effectiveness by effusion system. In this study, the semiempirical correlation (Eq.17) [20] is used. Other correlations can be customised and incorporated in the current framework.

$$
\begin{gathered}
\eta_{e}=1.9 \operatorname{Pr}^{2 / 3} /\left(1+0.329\left(C p_{\infty} / C p_{c}\right) \beta \xi^{0.8}\right) \\
\beta=1+1.5 E-4 R e_{c}\left(\mu_{c} W_{\infty} / \mu_{\infty} W_{c}\right) \sin \alpha
\end{gathered}
$$

$\operatorname{Pr}$ is Prandtl number of the coolant, $C p_{\infty}$ and $C p_{c}$ are the heat capacities for the coolant and freestream, $\mu_{c} \mu_{\infty}$ are the viscosities. $\alpha$ is the cooling hole angle. 
g) The element shown in Fig. 4 is subject to conduction (upper, left and right) radiation and convection (bottom) boundary conditions, the energy balance is applied to the central node $(\mathrm{j}, \mathrm{k})$. Thus, the discretised form of energy balance using Finite Difference Method becomes:

$$
\begin{gathered}
-k \Delta x \frac{T_{j, k}-T_{j, k+1}}{\Delta y}-k \frac{\Delta y}{2} \frac{\left(T_{j, k}-T_{j-1, k}\right)}{\Delta x}-k \frac{\Delta y}{2} \frac{\left(T_{j, k}-T_{j+1, k}\right)}{\Delta y}=h \Delta x\left(T_{j, k}-T_{c}\right)+0.5 \sigma_{0}(1+ \\
\left.\varepsilon_{w}\right) \varepsilon_{g} T_{g}{ }^{1.5}\left(T_{g}{ }^{2.5}-T_{j, k}{ }^{2.5}\right)
\end{gathered}
$$

$\varepsilon_{g}, \varepsilon_{w}$ are the emissivity of the gas and liner wall, $\sigma_{0}$ is the Stefan-Boltzman constant.

h) The temperatures at nodal points are numerically solved. The convergence criterion for obtaining the correct temperature is the heat balance on each node:

$$
\epsilon>\sum_{i=1}^{n}\left|\frac{T_{i+1}-T_{i}}{T_{i}}\right|
$$

i) Iteration of the geometric parameters is required if the liner wall temperature exceeds the temperature limit of the liner material.

\subsection{Performance}

A semi-empirical approach is proposed to evaluate relight efficiency. Initially, the mass flow, pressure, and temperature at altitude relight condition (i.e., windmilling condition) are estimated. The estimation requires the knowledge of the following input parameters:

- Maximum flight altitude $A L_{m}$

- Mach number $M_{a}$ at the maximum flight altitude

- Engine inlet area $A$

- Bypass ratio at the design point $B R_{d}$

- Overall pressure ratio at the design point $O P R_{d}$

- Specific take-off thrust under sea level static condition $T s_{t}$

Next, the combustor inlet windmilling pressure and temperature can be estimated based on windmilling performance data in Ref [21]. It should be noted the data is valid for turbojet, The factor is introduced to correct the pressure ratio and temperature ratio for turbofan application.

$$
F_{t f}=1-0.08 \times B P R
$$

BPR denotes the engine bypass ratio

Hence, the pressure ratio for turbofan is defined below

$$
P R_{t f}=\left(P R_{t j}-1\right) \times F_{t f}+1
$$

Similarly, the temperature ratio for turbofan is defined as:

$$
T R_{t f}=\left(T R_{t j}-1\right) \times F_{t f}+1
$$


The combustor windmilling inlet mass flow can be estimated based on airflow function defined in Eq.24 It requires the information for specific thrust under sea level static condition and Mach number during windmilling.

$$
\begin{gathered}
M F=w_{w m} \times\left(R \times T_{w m}\right)^{0.5} /\left(A_{c p} \times P \times f n(m a)\right) \\
f n(m a)=\gamma^{0.5} \times M a /\left(1+0.5(\gamma-1) \times M a^{2}\right)^{(0.5(\gamma+1) /(\gamma-1))}
\end{gathered}
$$

$w_{w m}, T_{w m}$ are the engine windmilling inlet mass flow and temperature. $A_{c p}$ is compressor area The combustor inlet mass flow can be finally estimated by assuming the BPR under windmilling condition is around 16 times the BPR at the design point. Once the windmilling parameters are available, the combustion efficiency level at the condition can be evaluated using the loading parameter defined in Eq.3. The relation is defined in Eq. 26 [21]

$$
\begin{gathered}
\eta=-5.46974 E-11 \Lambda^{5}+3.97923 E-8 \Lambda^{4}-8.73718 E-6 \Lambda^{3}+3 E \\
-4 \Lambda^{2}-0.004568246 \Lambda+99.7
\end{gathered}
$$

The above relation can be also used to assess the efficiency level at design-point and other engine operating conditions, by substituting the corresponding combustor inlet parameters into the loading parameter.

\section{Case studies}

\subsection{Aerodynamic sizing}

A case study is performed based on the existing modern low emissions combustors (i.e., CFM56-5SAC, GEnx-TAPS, and E3-DAC combustors) in the public domain. The take-off condition is chosen as the design point. For CFM56-SAC and GEnx-TAPS, part of the combustor inlet data is available from the open literature. (Table 5) Engine performance simulation was conducted using the software TurboMatch developed in Cranfield, to obtain the remaining performance parameters. The simulated results are also tabled and compared against the public-domain data in Table 2. It shows that the deviation between real and calculated results is within $1 \%$.

The flow distribution, main combustor dimension, and injector information are in Table 6. For GEnx-TAPS and E3-DAC, part of geometric data is available in Ref. [3] and [22]. With the available geometry (Fig.5), the actual dimensions for the remaining part of the combustor can be estimated by scaling. For comparison, the calculated results are also listed in the same table. For the rich burn combustor (i.e., CFM56), the design-point dome equivalence ratio is calculated to be 1.3. The ratio is estimated to be 0.6 for the lean-burn cases (i.e., GEnx and E3).

The results, in general, produce feasible dimensions and display reasonable agreement with the data. Most of the differences between the calculated results and data are within 10\%. A notable deviation occurs in the calculation of diffuser dimensions (i.e., GEnx-TAPS case). A small dump gap is believed to prevent flow separations in the faired diffuser. However, further reduction of the gap would lead to excessive local acceleration and a large flow turning angle, thereby increasing pressure loss. Since the effect of the dump gap on flow distribution and pressure loss is not studied in this case, the current study estimates the value to be 2 times the 
combustor inlet height. Split flow diffuser is used in E3 design. The study reveals that a 50\% reduction in pre-diffuser length can be achieved compared to a single passage configuration having the same area ratio. [1][22] The current design considers a single passage configuration, which results in a longer dimension.

\subsection{Emission}

The emissions are assessed on the same combustors in section 3.1, based on the available geometrical and performance information. Reactor layouts for each combustor are shown in Fig.6. The overall reactor layout for the SAC version (i.e., CFM56) was created. Flame front zone is modelled by PaSR to take account of the inhomogeneous effect of mixing owing to diffusion-based combustion. The downstream zones are simulated by two PSR considering the mixing process is enhanced due to air addition and increase of the flow residence time. A mixer is used to model the combustor exit. For E-3 DAC combustor, the network is established similarly to SAC but radially arranged. For internally staged configuration (Genx-TAPS), PaSR is chosen to model the diffusion combustion in the primary zone, and PSR is used to model the premixed combustion at the main stage. Near-wall cooling has a significant effect on emissions for this type of combustor [1]. Thus, near-wall reactors are created to model the lower gas temperature zone.

A comparison was made between the predicted results and the experimental data in ref [26]. The experimental results are measured under the four operating modes (idle 7\%, take-off $100 \%$, climb-out $85 \%$ and approach $30 \%$ ) at sea level, static and standard day conditions. The results show a reasonable agreement with experimental data in predicting NOx emissions at engine key power conditions. (Fig.7) Overall, the predicted results display a slight underestimation of the measured values. One of the reasons is from the kinetics calculations: for thermal NOx calculations, the Zeldovich mechanism is assumed to be decoupled from the main combustion process, by using the local equilibrium values of temperature, stable and free radicals. (e.g. $\left[N_{2}\right]$ $\left.\left[\mathrm{O}_{2}\right],[\mathrm{O}],[\mathrm{OH}]\right)$ In practice, the levels of concentrations are higher than their equilibrium levels, especially in the primary zone. The other source of error comes from the axial networking which was applied to simplify the flow characteristics. The primary zone recirculation effect is therefore not explicitly modelled, and thus the reactor flow residence time could be underestimated. However, the emission trends in general for different types of technologies were reasonably captured. It could be adopted to assess current and future technologies, which encourages conceptualisation for new technologies.

\subsection{Heat transfer and cooling}

The method used for heat transfer analysis was compared to the primary zone combustor liner wall temperatures measured from the experimental study in Ref [27]. The test was performed over pressure ranging from 10 to 26.7 atmospheres, at temperatures from 589 to $922 \mathrm{~K}$. Table 7 summarises the results. The measured liner wall temperatures show a strong dependence on the combustor inlet air temperature, which is captured by the calculation. The estimated values show the trend of increasing liner wall temperature with inlet temperature, which agrees with the experimental data. The predicted results are generally higher than the experimental values, with a maxim discrepancy of $9 \%$. The main source of error is from the flame temperature estimation. As shown in Table 8, the calculated primary zone temperatures are observed to be 
higher than the measured temperatures. The used Eric Goodger's approach assumes the temperature is adiabatic and is estimated by equating enthalpy balance. In practice, the process of fuel drop evaporation, fuel-air mixing and reaction are not complete, especially in the primary zone. Thus, the current approach generally overestimates the gas temperature and hence the radiation levels, leading to higher levels of liner temperature.

A second case study was conducted to verify the FDM approach. Two advanced cooling technologies were investigated (Table 9): Combined Impingement and Effusion cooling (Fig.4) and pure angled effusion cooling (absence of impingement wall). The geometries for the effusion cooling remain the same for the two cases. Fig.8 shows the calculated axial temperature distribution along the combustor liner. The analysis is restricted to a single cooling row. At the front sections, both cooling technologies yield similar temperature profiles with the temperature initially decreasing axially. The higher wall temperature for the combined system is due primarily to the cooling air takes the heat from the impingement along the backside of the liner surface before reaching the effusion holes. Downstream of the effusion hole, since the turbulence mixing process promotes the heat transfer process from the hot gas to the coolant, the cooling effectiveness decreases. This results in the increase in liner wall temperature, for both cases. With the presence of the jet impingement, the temperature can be reduced locally such that the overall peak temperature is minimised. The double-wall system gives a more efficient cooling performance than pure effusion.

The case studies show that the heat transfer calculation is believed to evaluate liner wall temperature with reasonable accuracy. The developed FDM is capable of capturing a 2Dimensional global prediction on liner temperature distributions for different cooling systems, as well as producing the physically sensible temperature predictions. It could be of use in the rapid identification of design solutions as well as initiating the optimisation of the design variables.

\subsection{Performance}

Due to more open literature data that are available for CFM56-SAC and GEnx-TAPS cases, the combustion efficiencies are evaluated using the loading parameter $\Lambda$ (E.q.2.3). At altitude relight, the combustor inlet windmilling parameters are estimated by the proposed method (section 2.5). In addition to the aerothermal parameters, combustor volume is also a key parameter to govern the efficiencies. A sufficient increase in volume results in longer flow residence time, which reduces the loading and facilities the combustion. However, further reduces the loading leads to unnecessary large dimensions and weight penalties. For each case, the relight altitude is assumed to be the same as the corresponding cruise altitude. For comparisons, the altitude relight and take-off efficiency levels are also presented in the same table. As indicated in Table 10, the predicted altitude relight efficiencies for the two cases are both higher than the minimum acceptable level, which is usually 80\% [28][29]. Modern combustors effectively achieve combustion efficiency of nearly $100 \%$ for most of the high power operating conditions. [12][21][28][29] The predicted efficiencies for the two combustors at take-off condition show the agreement with the value. Based on the reasonable altitude relight efficiency predicted, the approach may be used to provide an indicative assessment of combustor relight capability at the preliminary design phase. 


\section{Methodology application}

\subsection{Conceptual lean staged combustor}

This section aims to apply the developed methodology to a conceptual lean staged combustor used for a smaller aero gas turbine. The take-off condition is chosen to be the design point. Combustor inlet data and design targets are listed in Table 11. Additionally, the geometrical constraints are also defined; namely, the combustor inlet and outlet locations, axial length limit, upper and lower casing limits are imposed. Jet A-1 is used as fuel.

The framework enables the automatic design process for the development of a conceptual lean staged low emissions combustor (Fig.9). The combined faired and dumped diffuser configuration is chosen to reduce the inlet flow Mach number with minimised pressure loss. All the air for combustion enters through the fuel-air mixer. Fuel staging is employed to address the low power stability issue, with local pilot stage equivalence ratio at idle close to stoichiometric value. Table 12 shows the air and fuel distribution results. The primary hole and dilution zone are eliminated since the mixing is primarily achieved via the fuel-air mixer. The centre recirculation zone is established by the dome swirlers. The dome height is reasonably increased to reduce the dome airflow velocity, which promotes stable ignition and combustion, especially during the engine altitude relight. For the fuel-air mixer, the pilot stage adopts nonpremixed combustion which effectively reduces the flashback risks. The pilot mixer comprises a pressure swirl atomiser, a two-stage air swirler, and a Venturi assembly. The primary swirler is responsible for fuel atomisation and the secondary swirler is to control the flow structure. The pilot swirling strength is sufficiently raised to initiate a relatively wide cone angle from the pilot outlet, which improves the ignition performance. In this case, the pilot overall swirl number is 0.6 .

For the main stage, the current design employees partially premixed combustion. It consists of a mixing chamber, a fuel-air mixer that combines the multi-point cross-flow injection with an axial type of the air swirler. The number of the fuel orifice in cross-flow is equal to the number of the swirler vane, which is to enhance mixing in the circumferential direction. To control the auto-ignition, the mixing chamber of the main is designed such that the mean flow residence time does not exceed auto-ignition delays. A safety factor of 2 is imposed. The swirling strength of the main stage is reasonably reduced to some extent so that the axial flow speed along the centreline of the mixer can be increased to provide the resistance of the vertex bubble from moving upstream. Thus, the flashback can be effectively reduced. In this case, the swirl number of the main is around 0.45 .

The impingement with angled effusion cooling is selected for the outer liner. For the inner liner annulus, the angled effusion cooling AEC is adopted. For the effusion system, the hole angle is 20 degree and the hole diameter is around $0.7 \mathrm{~mm}$. The spacing to the hole diameter ratio is around 4 . For impingement system, the hole has a similar dimension, the impingement location is 0.75 of the total segmental length. 


\subsection{Design Evaluation}

\section{Emissions}

The emissions are assessed based on the developed physics-based method. Overall, the designed combustor produces $\mathrm{NO}_{\mathrm{x}}$ emissions increasing with power settings (Fig. 10) with take-off EI $\mathrm{I}_{\mathrm{NOx}}$ peaks at $8.2 \mathrm{~g} / \mathrm{kg}$. The exception is at mid-cruise. During mid-cruise, since the fuel is consumed during flight, the aircraft body is getting lighter. Therefore, less mission fuel is required. This results in a leaner burn in the combustor primary zone. In order to alleviate the risk of lean blowout, the fuel schedule (Fig.10) is employed such that part of the main is turned off. With this strategy, the local equivalence ratio and thus flame temperature can be raised. The result indicates the emission level is less than idle emission, which results from the local richer burn at the pilot only operating mode.

\section{Liner wall temperature}

The liner wall temperatures are evaluated using the developed FDM method. The maximum liner wall temperature is predicted for each key engine power condition. (Table 13) The highest peak temperature of $1060.4 \mathrm{~K}$ is identified at maximum power. For low power stability, the pilot is only operating with the richer combustion $(\phi=1.3)$ initiated at approach. The local gas temperature is raised so that the higher flame radiation is transferred to the liner wall surface. As a consequence, the peak temperature at the approach is observed to be higher than those at start and mid-cruise.

\section{Performance}

For performance evaluation, in addition to take-off condition, it also considers idle, approach, cruise (start of cruise), mid-cruise, and climb. (Table 14) The analysis yields altitude relight combustion efficiency of $84 \%$ and is greater than the minimum acceptable level (i.e., $80 \%$ ). The predicted combustion efficiencies show they increase with engine thrust with the efficiency level is $99.7 \%$ at maximum power condition.

\subsection{Sensitivity analysis}

A sensitivity analysis (Table 15 ) was performed to assess the impact of design assumptions on the combustor sizing (i.e., prediffuser length $L_{p d}$, dome, passage, and casing height $H_{d}, H_{p}$, $H_{c}$, liner length $L_{l}$, Combustor volume $V_{l}$ impingement location $X_{D}$, and double wall slot: $H_{s}$ ) and performance outcomes. (prediffuser and liner pressure loss $\Delta P_{d} / P_{3}, \Delta P_{l} / P_{3}$, altitude relight combustion efficiency $\eta_{a l}$, NOx emission $E I_{N O x}$, and maximum liner wall temperature $T_{\max }$ ) Based on the deviations from the initial calculations, the level of variation in design outcome is classified as: below $1 \%$ (small variations), $1 \%-5 \%$ (moderate variations), $5 \%-10 \%$ (medium variations) and above $10 \%$. (notable variations)

The change in passage velocity $V_{p}$ mainly impacts on passage and casing dimensions. In terms of combustor performance, the liner wall temperature is dramatically affected due primarily to the influence of external convection of the liner.

The design variable dome equivalence ratio $\phi_{d}$ is believed to have a most significant impact on combustor design and performances. In particular, the dimensions of dome and casing 
change notably. The change in $\phi_{d}$ results in significant variations in flame temperature and radiation to the liner, which greatly influences the emission level and liner wall temperature.

The dump gap $D_{d}$ was assumed in the initial calculation. This parameter has a notable impact on the geometry of the pre-diffuser and hence the pressure loss.

The dimension of the combustor volume was evaluated using the semi-empirical loading parameter that is valid for the specific combustors. The pressure and temperature dependent coefficients in the parameter can vary for different combustors types. The values initially used in the calculations are $a=1.8, b=0.00145$, and $c=400$. [21] Analysis indicates that the pressuredependent coefficient, a is the most critical term that impacts the combustor sizing as well as emission and liner wall temperature due primarily to the change in flow residence time and coolant mass flow per unit of liner surface area.

Axial networking was applied in the emission calculations, and the flow recirculation effect is not explicitly modelled in the physical-based method. In this analysis, the effect of flow recirculation on NOx emission is studied by varying the reactor flow residence time $\tau$. It can be observed that the emission level is mainly governed by residence time in the flame front zone $\tau_{f}$ compared to it in downstream zones $\tau_{d}$.

The geometrical cooling design variables: impingement location and double wall gap both lead to notable impact to the cooling performance.

\section{Optimisation study}

There are a number of conflicting design targets that exist in combustor design. The conventional iterative process by changing the design variables is inefficient to give optimum solutions. Therefore, multi-objective optimisation techniques are used to address the issue with conflicting requirements especially when one (or more) could not be met.

The designed combustor in section 4 indicates that the combustion efficiency and liner temperature meet the design requirement. However, the NOx emission is greater than the required value. The optimisation was conducted at the design-point. By conducting the parametric analysis at the design-point condition, the combustor meets the required efficiency level. Therefore, a focus is placed on the emission and liner temperature. For smaller gas turbines, the air mass flow is reduced and the ratio of combustor surface area to volume is relatively large, both result in a challenge in combustor liners cooling. In addition, a large proportion of the airflow is employed for lean combustion to control $\mathrm{NO}_{\mathrm{x}}$ emissions. This also leads to less air available that is challenging to maintain the low liner temperature. The notable conflicting design requirements lead to the optimal use of air and change of cooling geometries to control the emission and liner wall temperature.

Based on the classification of the optimisation problem, the current optimisation work is classified as 1) non-linearity, the problem to be solved presents a non-linear behaviour, and it is believed to be non-smooth and non-differentiable 2) Multi-objective, two objectives are to be investigated in this optimisation study, namely the NOx emission and liner wall temperature 3 ) constrained, the parameters are constrained with certain ranges to limit the objective space

4) Real values: all variables in the optimisation problem are real numbers A controlled elitist genetic algorithm optimiser, a variant of NSGA-II, is incorporated in the current framework. 
- Input

Since the design process can be automated using the optimisation techniques, the following design parameters should be considered as inputs:

1) Combustor inlet/outlet $P_{3,4}, T_{3,4}, W_{3,4}$,

2) Combustor architecture

3) Fuel type, fuel mass flow $W_{f}$, and lower heating value LHV

4) Inlet/outlet pitch location and flow area

5) Geometrical constraints of the combustor

- Objectives

As mentioned above, as the current design meets the efficiency requirement, the main objectives in this design are focused on combustor emission and liner temperature.

Therefore, the fitness functions $f(X)$ comprises two objective functions are defined as:

$$
\begin{aligned}
& f_{1}(X)=\min _{-} E I_{N O x} \\
& f_{2}(X)=\text { min_T } T_{\text {liner }}
\end{aligned}
$$

$X$ is a vector that contains design variables

The first objective function $f_{1}(X)$ aims to reduce the take-off NOx emission using the reactor algorithm in section 2.5. The second function $f_{2}(X)$ aims to control the liner temperature and maintain its integrity using the FDM in section 2.6.

- Variables

The sensitivity study (4.3) indicates that the dome airflow distribution greatly impacts the emission and liner temperatures. Hence, the primary zone airflow parameter is selected as an optimising variable. The geometrical parameters affect cooling performance. As mentioned in 2.4, during the cooling geometry calculations, the axial impingement position and height of the double-wall cooling are assumed design variables. From the sensitivity analysis, both parameters display sensitive behaviours and have substantial impacts on the liner temperature. Therefore, they are also selected as main variables in the optimisation process.

Thus, the defined variables are:

$$
X=\left(X_{1}, X_{2}, X_{3}\right)
$$

$X_{1}$ : a fraction of the air mass flow in the primary zone $\mu_{p z}\left(0.468 \leq \mu_{p z} \leq 0.85\right) . X_{1}$ governs the air distribution through the combustor, increasing the cooling airflow would initially reduce the liner wall temperature. Further increase in cooling airflow leads to less air for combustion, this results in combustion close to stoichiometric burn that enhances the gas radiation to the liner wall. This presents a cooling challenge although cooling airflow is increased. The range of $X_{1}$ is defined based on the primary zone loading to decrease the NOx emission as well as reduce the risks of the lean blowout. 
$X_{2}$ : the axial location of the impingement $X_{D}$, namely the ratio of the distance from the trailing to the diameter of the cooling hole $\left(0.5 \leq X_{D} \leq 0.9\right) . X_{2}$ is suggested not to be either too close or far away from the cooling hole.

$X_{3}$ : the height of the double-wall cooling slot $H_{s},\left(0.001 \leq H_{s} \leq 0.004\right)$. Reduction of $X_{3}$ is believed to enhance the passage flow speed and hence convection process. However, the impingement jet requires a sufficient gap for better impingement performance. [30]

\section{- Coupled algorithms}

In order to find the optimum solutions to achieve the combustor emission and liner temperature goals, the related design tools should be integrated to conduct the optimisation task. Thus, the following algorithms are coupled in this problem:

1) Flow distribution

2) Combustor sizing

3) Emission

4) Heat transfer and cooling

5) Optimisation

- Constraints

Based on the current design criteria which require the NOx emission at take-off condition is below $6 \mathrm{~g} / \mathrm{kg}$ and the maximum permitted liner wall temperature is $1123 \mathrm{~K}$, these two parameters are constrained in non-linear inequality form.

$$
E I_{N O x} \leq 6 ; T_{m} \leq 1123
$$

$T_{m}$ is the maximum temperature identified in the combustor liner

The stall generation is set to be 100 , and the function tolerance is 1e-4. Both setting parameters were tested and produce non-sensitive solutions. The optimiser produces the solutions shown in Fig.11. The shape of the Pareto front illustrates the objectives are in the form of the conflicting nature. The set of the optimal solutions yields the maximum liner wall temperature ranging from $995 \mathrm{~K}$ to $1013 \mathrm{~K}$ and the $\mathrm{NO}_{\mathrm{X}}$ emissions from 2.8 to $3.25 \mathrm{~g} / \mathrm{kg}$. The produced sets of solutions satisfy the target at the design-point condition. The ranges for the corresponding design vectors are: $0.74 \leq X_{1} \leq 0.81,0.76 \leq X_{2} \leq 0.80,0.0031 \leq X_{3} \leq 0.0036$

It should be noted that the solutions are non-dominated and each point on the Pareto front curve can be regarded as an optimum solution. For selecting the final optimum point, decision making is required. This process is dependent on the personal choice of the designers and not further considered in the present work. However, some multi-attribute decision-making methods are available to help the designer to determine the final optimal point. These include Additive Utility method [33], TOPSIS method [34] and CODASID method. [35]

Overall, the optimisation study using the developed methodology indicates that the developed work has the potential of identifying and resolving the potential design challenges at the early stages of the design process. In the future development, more design objectives (i.e., altitude relight combustion efficiency and outlet temperature distribution) will be coupled in the framework to allow more design variables to be optimised. 


\section{Conclusions}

A detailed preliminary design methodology was developed for modern low emissions aero combustors. The inter-related design elements involving aerodynamic sizing, heat transfer and cooling, emission and performance are coupled in the design process. Different approaches are provided in detail.

Case studies were performed to assess the feasibility of developed work. The developed combustor sizing methodology produces reasonable combustor dimensions against real low emissions combustors in the public domain, namely CFM56-5SAC GEnx-TAPS, and E3-DAC combustors. The difference between most of the results is below $\pm 10 \%$.

The developed physics-based method is used to predict chemical emission. It provides a good agreement with experimental data, with the capability of producing a reasonable trend to represent the NOx emissions as a function of engine power setting.

The case studies show that the heat transfer calculation is believed to evaluate liner wall temperature with reasonable accuracy. The Finite Difference Method FDM is developed and applied to the modern cooling system (Effusion, and impingement + effusion). It is useful to identify to the potential peak temperature (and location) hence liner durability prediction; the physically sensible trends resulting from the parametric studies indicate that the developed FDM could be used for optimisation and is capable of identifying the cooling solution in a relatively short timeframe, which is of great help in the preliminary design phase.

The methodology was then applied to design a conceptual lean staged combustor. A sensitivity analysis was performed and assess the impact of the design assumptions on outcomes. The overall performance of the designed combustor is then predicted. It shows the emission exceeds the design target. The optimisation of the air distribution and cooling geometrical parameters addresses the trade-off between the NOx emissions and liner wall cooling.

The developed design framework demonstrates the capability of rapid design space exploration and identification of different design solutions. It demonstrates the proposed methodology enables the automatic design process for the development of a conceptual lean staged low emissions combustor. The optimisation to addresses the trade-off between the NOx emissions and liner wall cooling, which shows that the developed work is capable of identifying and resolving the potential design challenges at the early stages of the design process.

\section{Acknowledgment}

The authors would like to thank the AECC Hunan Aviation Powerplant Research Institute for funding the research. 


\section{Reference}

[1] Liu, Y., Sun, X., Sethi, V., Nalianda, D., Li, Y.G. and Wang, L., 2017. Review of modern low emissions combustion technologies for aero gas turbine engines. Progress in Aerospace Sciences, 94 , pp.12-45.

[2] Lazik, W., Doerr, T. and Bake, S., 2007. Low NOx combustor development for the engine 3E core engine demonstrator. In XVIII International Symposium on Air Breathing Engines (ISABE), Beijing, China, Sept (pp. 2-7).

[3] Foust, M., Thomsen, D., Stickles, R., Cooper, C. and Dodds, W., 2012. Development of the GE aviation low emissions TAPS combustor for next generation aircraft engines. In 50th AIAA aerospace sciences meeting including the new horizons forum and aerospace exposition (p. 936).

[4] Stuttaford, P. and Rubini, P., 1997. Preliminary gas turbine combustor design using a network approach. Journal of engineering for gas turbines and power, 119(3), pp.546-552.

[5] Mohammad, B. and Jeng, S.M., 2009, August. Design Procedures and a Developed Computer Code for Single Annular Combustor Preliminary Design. In 45th AIAA/ASME/SAE/ASEE Joint Propulsion Conference \& Exhibit (p. 5208).

[6] Khandelwal, B., Banjo, O. and Sethi, V., 2014. Design, evaluation and performance analysis of staged low emission combustors. Journal of Engineering for Gas Turbines and Power, 136(10), p.101501.

[7] Mark, C.P. and Selwyn, A., 2016. Design and analysis of annular combustion chamber of a low bypass turbofan engine in a jet trainer aircraft. Propulsion and power research, 5(2), pp.97-107.

[8] Li, J., Sun, X., Liu, Y. and Sethi, V., 2017. Preliminary aerodynamic design methodology for aero engine lean direct injection combustors. The Aeronautical Journal, 121(1242), pp.1087-1108.

[9] Roshan D.K., Burela R.S., Kushari A. (2019) Design Philosophy for a Laboratory Scale Gas Turbine Combustor. In: Innovations in Sustainable Energy and Cleaner Environment. Green Energy and Technology. Springer, Singapore

[10] Leishman, J. G., 2000 “Principle of Helicopter Aerodynamics, Cambridge University Press, Cambridge, United Kingdom,

[11] Mellor, A.M., Design of Modern Gas Turbine Combustors, pp. 361-362, Academic Press, San Diego, CA, 1999

[12]Mattingly, J.D., Heiser, W.H., and Pratt, D.T., 2002. Aircraft engine design. American Institute of Aeronautics and Astronautics.

[13]Guin, C., 1999. Characterisation of autoignition and flashback in premixed injection systems. In RTO Meeting proceedings.

[14] Sheen, H.J., Chen, W.J., Jeng, S.Y. and Huang, T.L., 1996. Correlation of swirl number for a radial-type swirl generator. Experimental thermal and fluid science, 12(4), pp.444-451.

[15] Bogard, D.G. and Thole, K.A., 2006. Gas turbine film cooling. Journal of propulsion and power, 22(2), pp.249-270.

[16] Tim. C. Lieuwen and Vigor. Yang. Gas turbine emissions, Cambridge University Press, 2013. 
[17] De Soete, G.G., 1975, January. Overall reaction rates of NO and N2 formation from fuel nitrogen. In Symposium (international) on combustion (Vol. 15, No. 1, pp. 1093-1102). Elsevier.

[18] Chemical Equilibrium with Applications (CEA) https://www.grc.nasa.gov/WWW/CEAWeb/, (accessed on 09/03/2019)

[19] Goodger, E.M. and Ogaji, S.O., 2011. Fuels \& Combustion in heat engines. Cranfield University Press.

[20] Boyle, R.J. and Ameri, A.A., 2010, October. A correlation approach to predicting film cooled turbine vane heat transfer. In ASME Turbo Expo 2010: Power for Land, Sea, and Air (pp. 1841-1856). American Society of Mechanical Engineers

[21] Walsh P and Fletcher P. Gas turbine performance. John Wiley \& Sons, pg.511-512, 2004

[22] Burrus, D.L., Chahrour, C.A., Foltz, H.L., Sabla, P.E., Seto, S.P. and Taylor, J.R., 1990. Energy Efficient Engine combustor test hardware detailed design report.

[23] Dodds. W, Engine and aircraft technologies to reduce emissions, in UC Technology Transfer Symposium - Dreams of Flight. San Diego, USA, 2002 (1 March).

[24] Daly, M. Jane's aero-engines, IHS Jane's, Coulsdon. 2014

[25] https://www.geaviation.com/commercial/engines/genx-engine (accessed on 25/04/19)

[26] ICAO emission data bank https://www.easa.europa.eu/easa-and-you/environment/icaoaircraft-engine-emissions-databank (accessed on 25/04/19)

[27] Norgren, C.T., 1973. Comparison of primary zone combustor liner wall temperatures with calculated predictions.

[28] Mongia, H.C., 2014. Future Trends in Commercial Aviation Engines' Combustion. In Novel Combustion Concepts for Sustainable Energy Development (pp. 113-176). Springer, New Delhi.

[29] Lefebvre, A.H. and Ballal, D.R., 2010. Gas turbine combustion: alternative fuels and emissions. CRC press.

[30] Viskanta, "Heat transfer to Impinging Isothermal Gas and Flame Jets," Experimental Thermal and Fluid Science, vol. 6, pp. 111-134, 1993.

[31] Wei-hua, Y., Jun, C., Rui, S., Xu-Sheng, H. and Shuang-wen, S., 2011. Experimental investigation on impingement-effusion film-cooling behaviors in curve section. Acta Astronautica, 68(11-12), pp.1782-1789.

[32] Lefebvre, A.H. and McDonell, V.G., 2017. Atomization and sprays. CRC press.

[33] Jacquet-Lagreze, E. and Siskos, J., 1982. Assessing a set of additive utility functions for multicriteria decision-making, the UTA method. European journal of operational research, 10(2), pp.151-164.

[34] Tzeng, G.H. and Huang, J.J., 2011. Multiple attribute decision making: methods and applications. Chapman and Hall/CRC.

[35] Sen, P. and Yang, J.B., 1994. Design decision making based upon multiple attribute evaluations and minimal preference information. Mathematical and computer modelling, 20(3), pp.107-124 


\section{Figures}

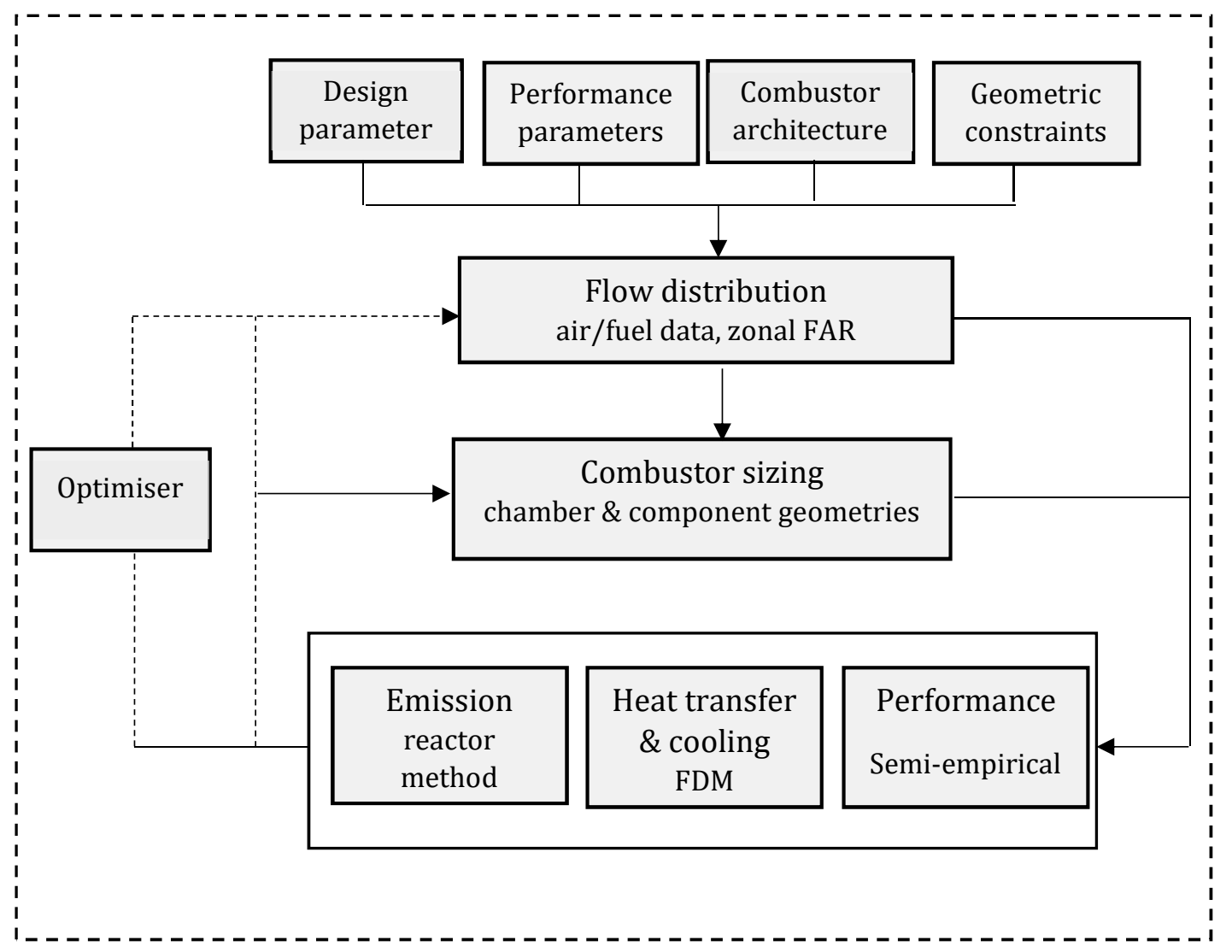

Figure 1. Preliminary design framework- global design process

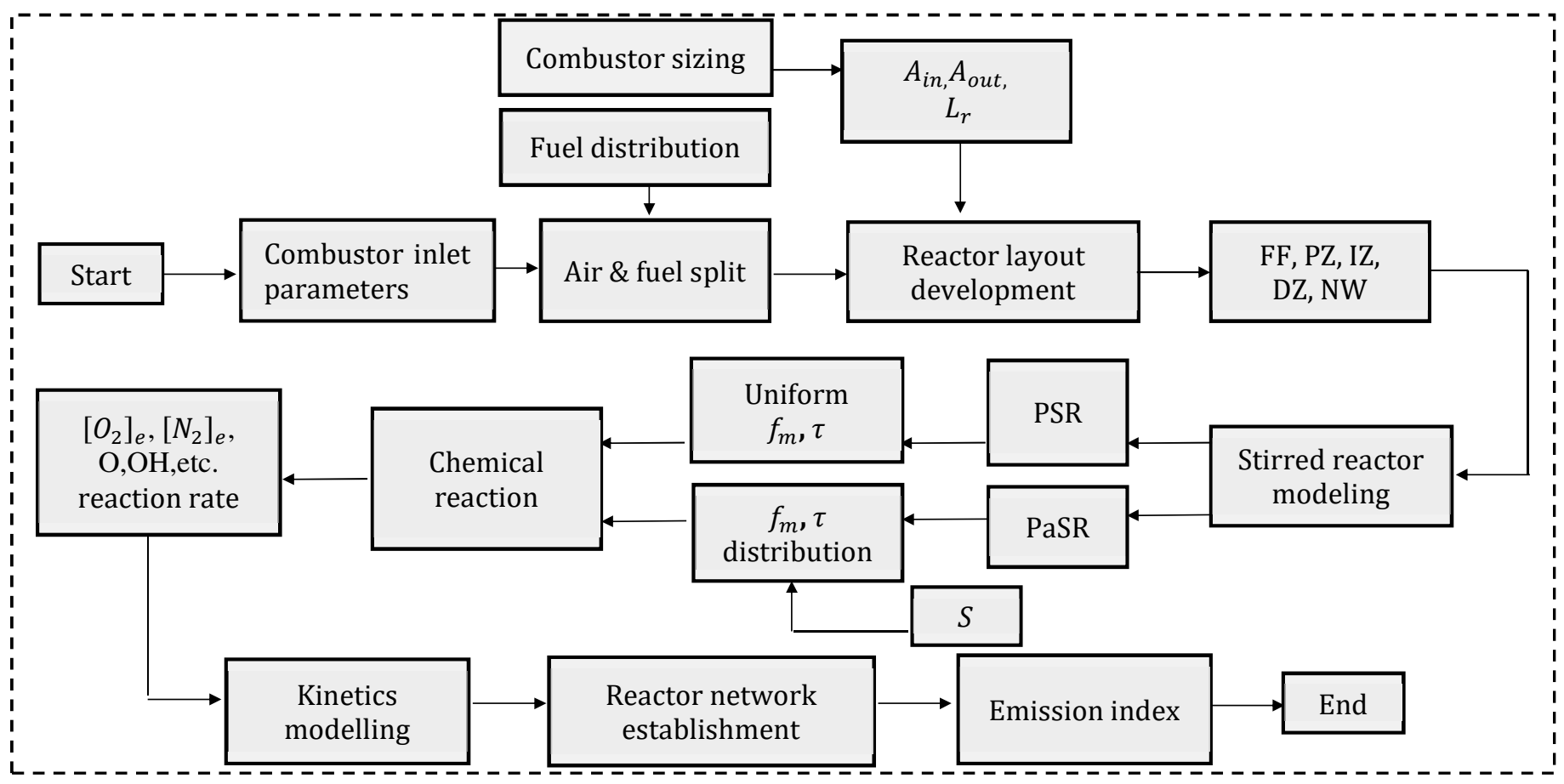

Figure 2. Emissions calculation process 


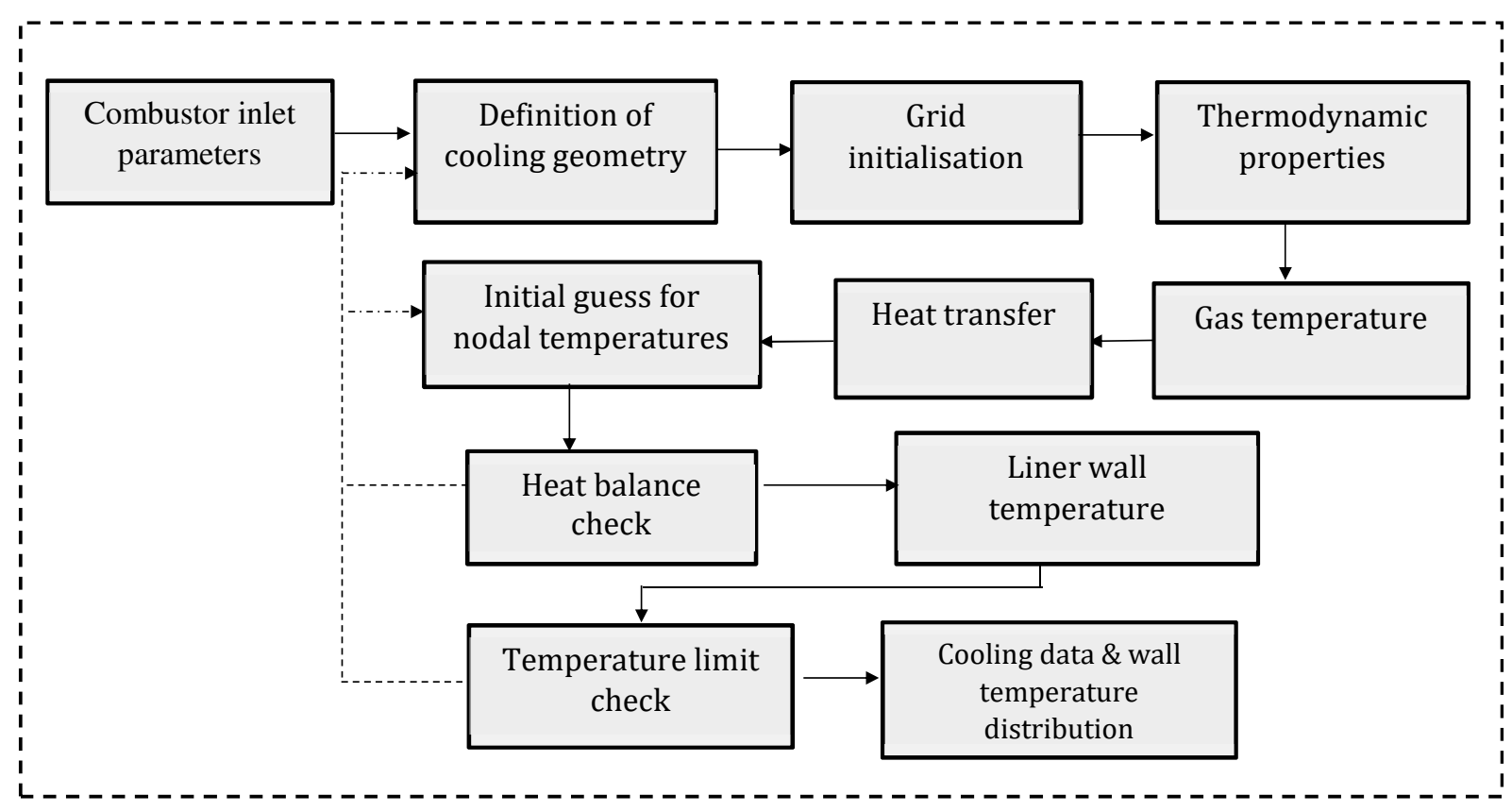

Figure 3. Heat transfer and cooling analysis- Finite Difference Method

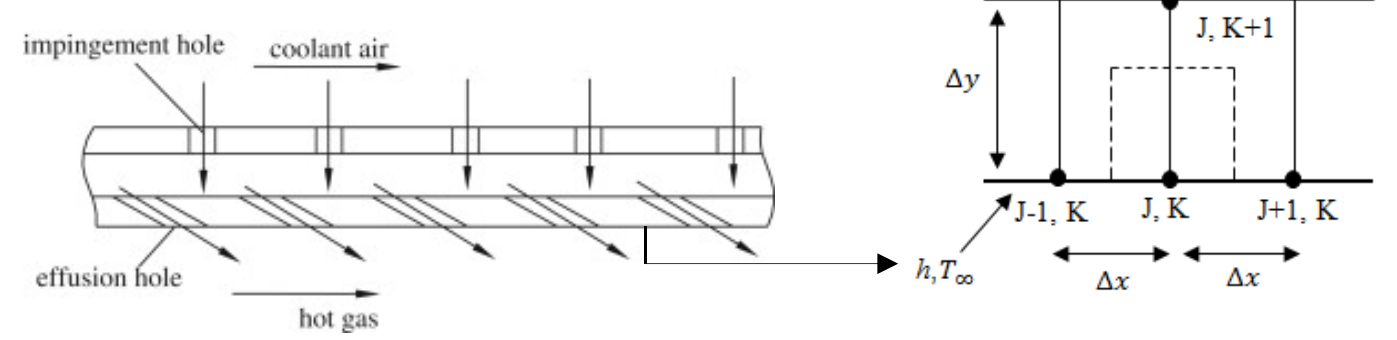

Figure 4 - Combined cooling system [31] - nodes with radiation and convention boundary
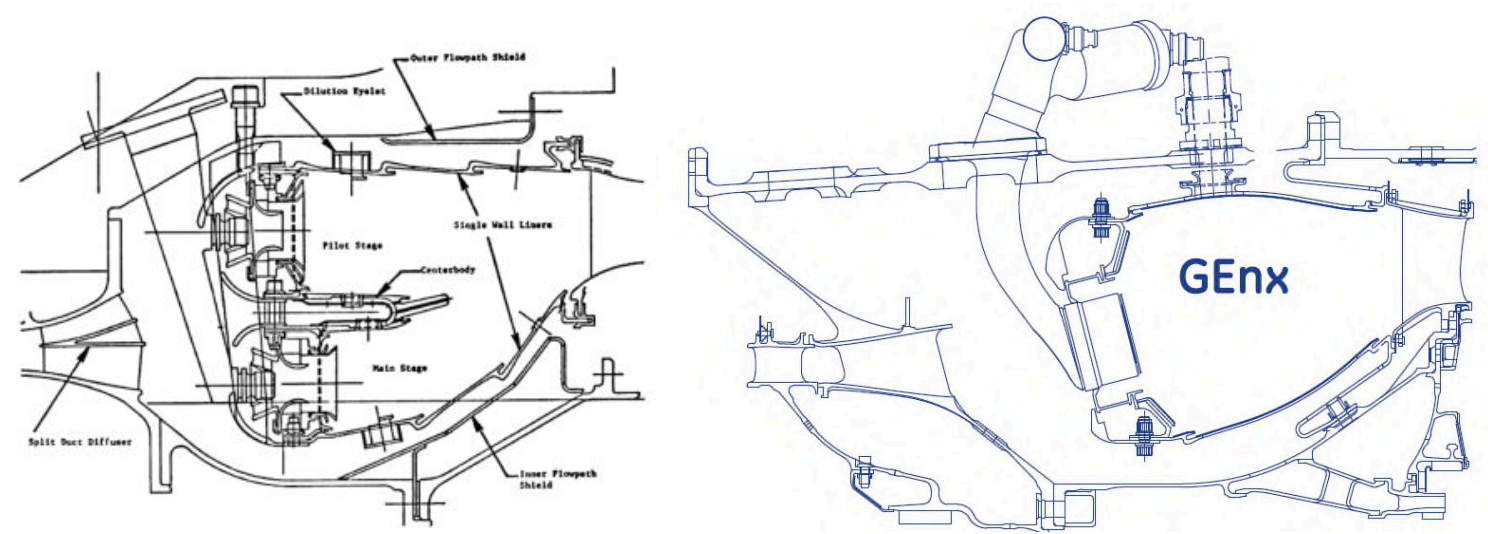

Figure 5. E3-DAC and GEnx-TAPS combustors [3][22] 

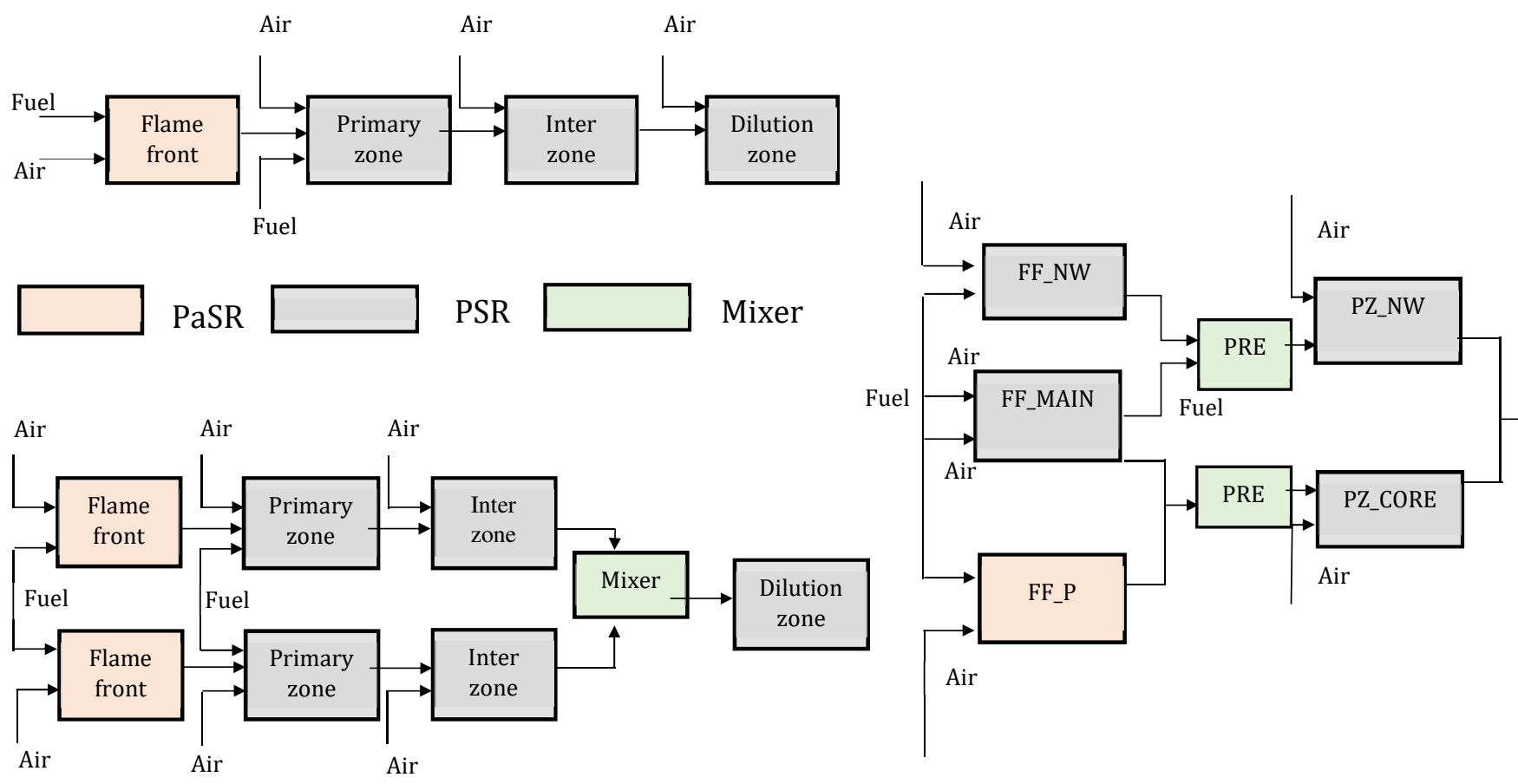

Figure 6- Reactor layout representaion for SAC (top left), DAC (bottom left) and Internally staged configuration (right).

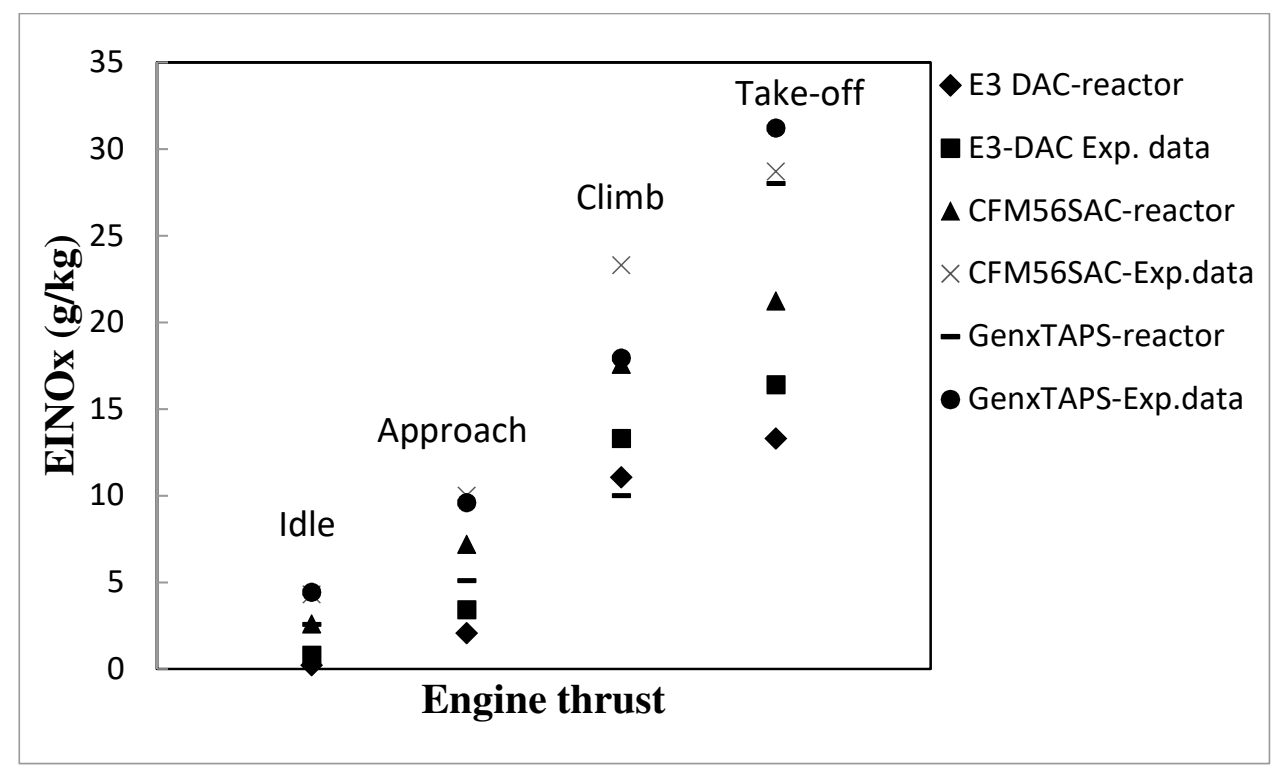

Figure 7- Emission index- experimental data vs calculated resutls 


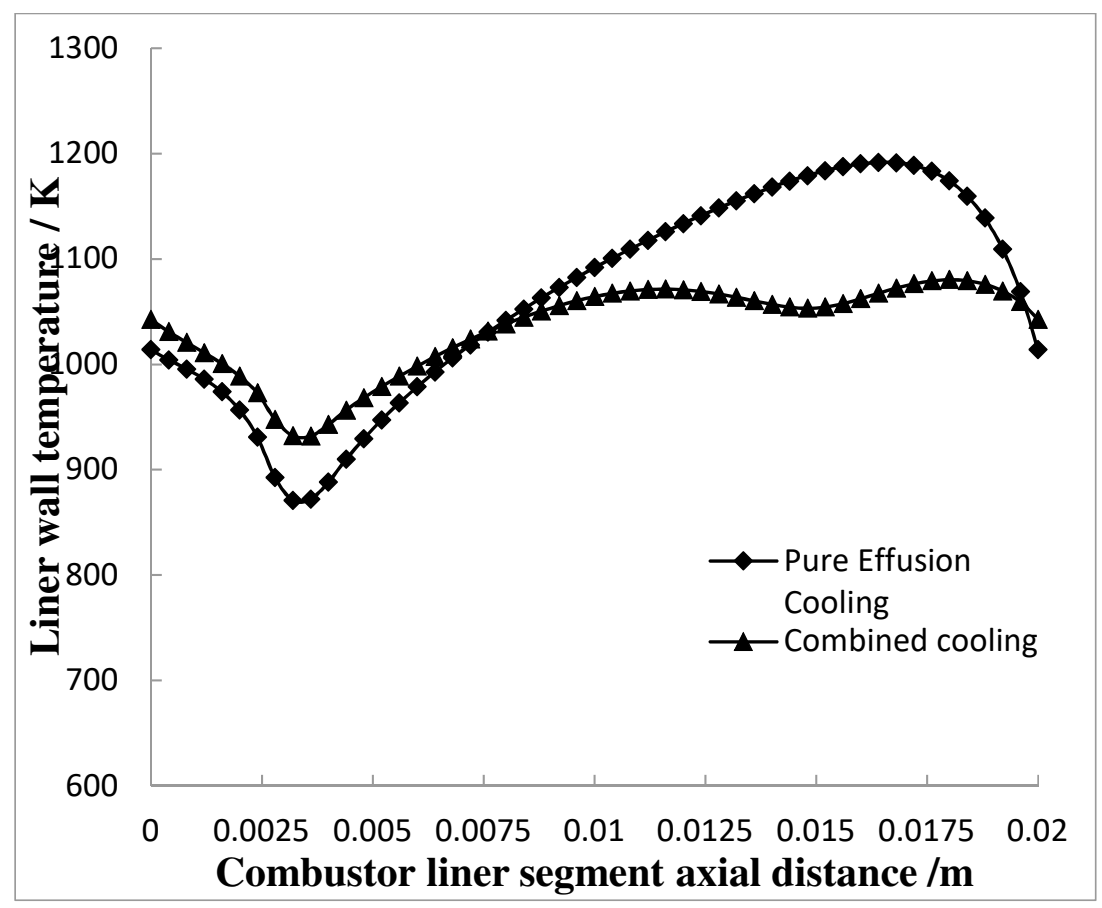

Figure 8. Liner wall temperature distribution for two cooling technologies
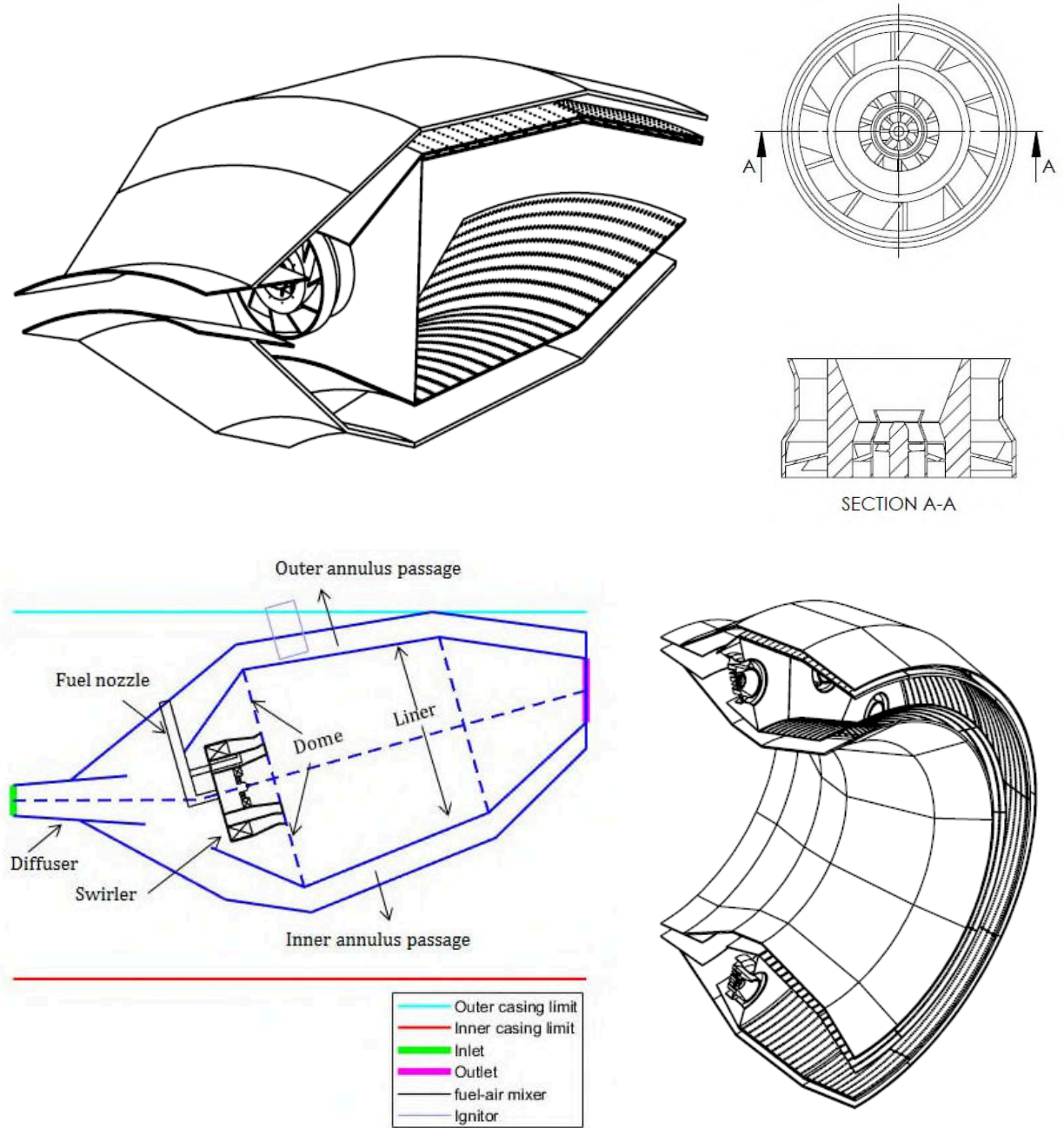

Figure 9. Designed conceptual lean staged combustor. 


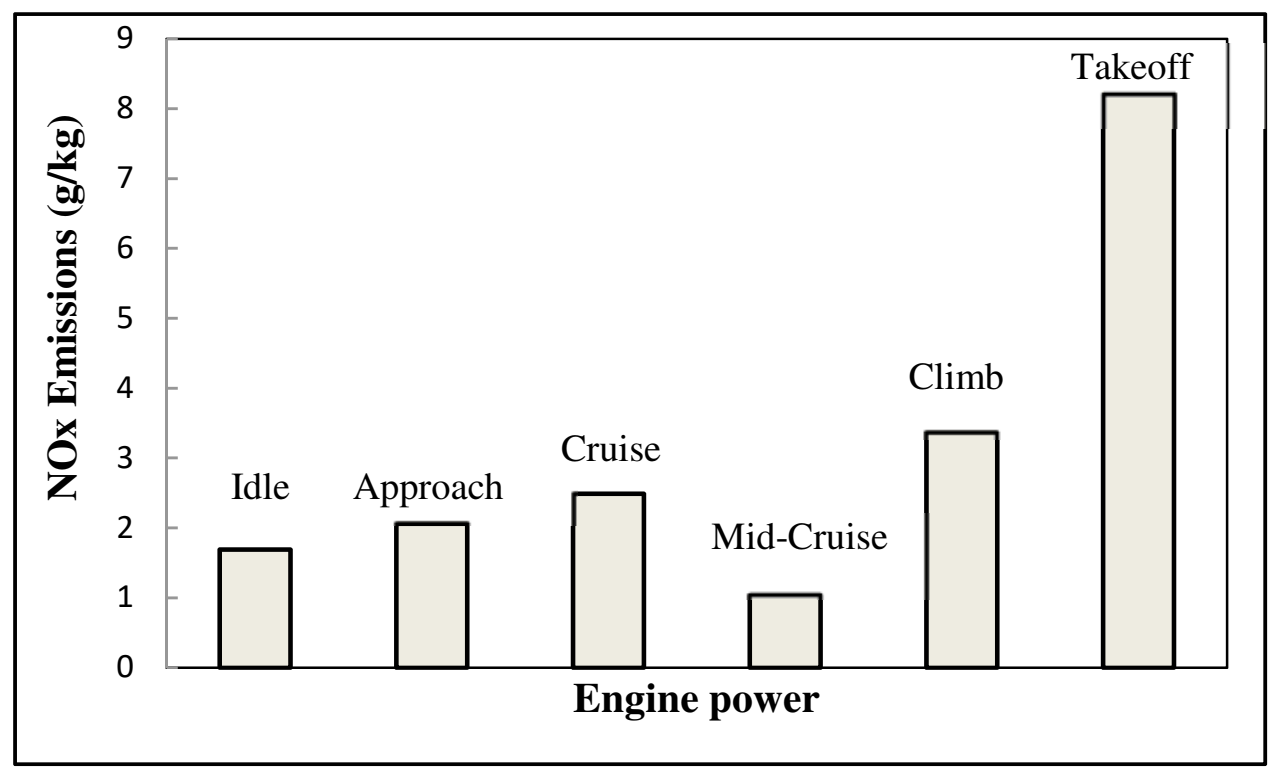

\begin{tabular}{lllllll}
\hline $\begin{array}{l}\text { Operating } \\
\text { condition }\end{array}$ & Idle & Approach & Cruise & $\begin{array}{l}\text { Mid- } \\
\text { Cruise }\end{array}$ & Climb & $\begin{array}{l}\text { Take- } \\
\text { off }\end{array}$ \\
\hline $\begin{array}{l}\text { Schedule } \\
\text { mode }\end{array}$ & Pilot & Pilot & $\begin{array}{l}\text { Pilot }+ \\
\text { only }\end{array}$ & $\begin{array}{l}\text { Pilot +Part } \\
\text { only }\end{array}$ & $\begin{array}{l}\text { Pilot } \\
\text { main }\end{array}$ & $\begin{array}{l}\text { Pilot } \\
+ \text { of Main }\end{array}$ \\
\hline
\end{tabular}

Figure 10. NOx emission at key engine power conditions and fuel schedule mode

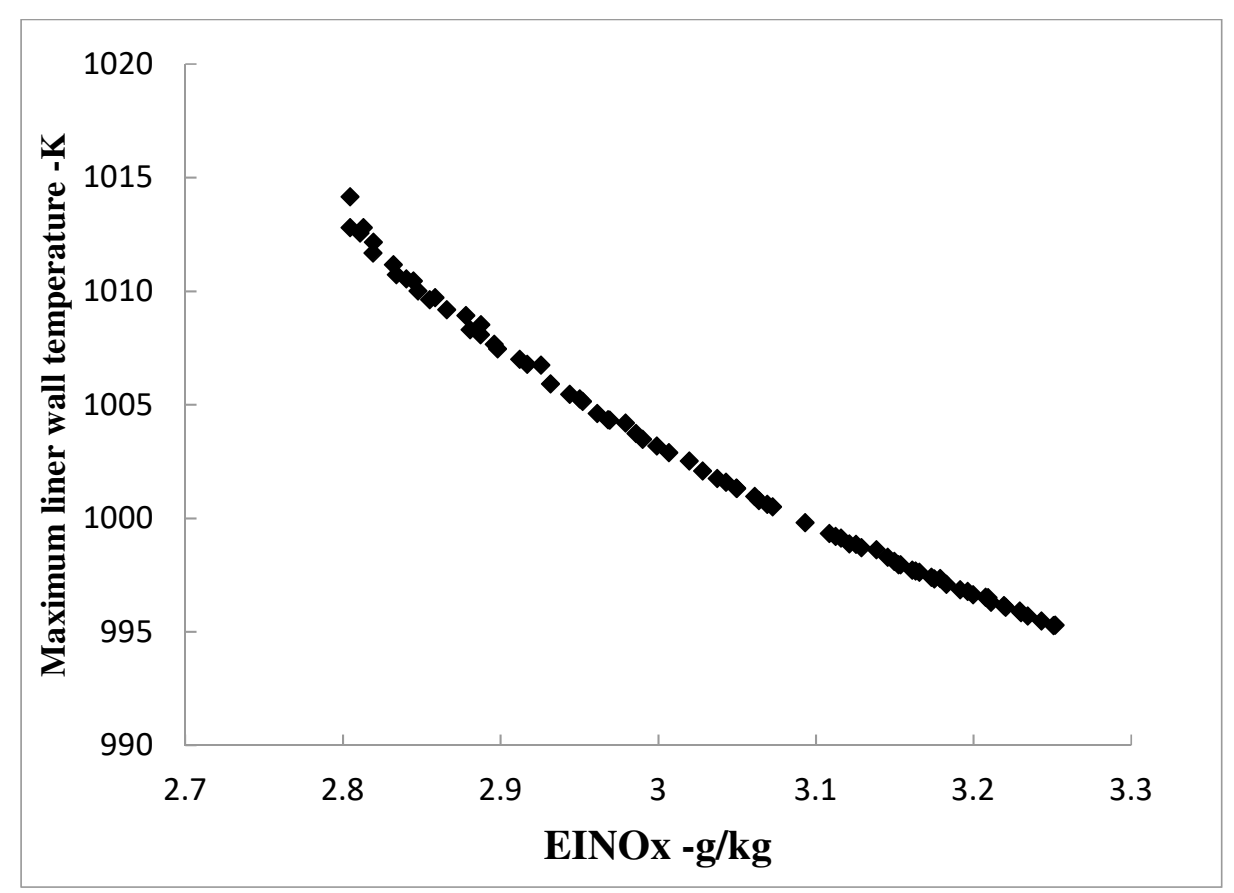

Figure 11. Pareto front for NOx emissions vs Maximum liner wall temperature 
Tables

\begin{tabular}{l|l|l|l}
\hline $\begin{array}{l}\text { Aerothermal } \\
\text { parameters }\end{array}$ & $\begin{array}{l}\text { Geometric } \\
\text { parameters }\end{array}$ & $\begin{array}{l}\text { Performance } \\
\text { parameters }\end{array}$ & $\begin{array}{l}\text { Geometric } \\
\text { constraints }\end{array}$ \\
\hline Inlet pressure $\mathrm{P}_{3}$ & Inlet pitch radius $\mathrm{r}_{3}$ & Combustion efficiency $\eta$ & Max. axial length \\
Inlet temperature $\mathrm{T}_{3}$ & Outlet pitch radius $\mathrm{r}_{4}$ & Emission index EI & $\mathrm{L}_{\text {am }}$ \\
Inlet air mass flow $\mathrm{W}_{3}$ & Inlet flow area $\mathrm{A}_{3}$ & Max. pressure drop $\Delta \mathrm{P}$ & Max. casing height \\
Fuel type and $\mathrm{LHV}$ & Outlet flow area $\mathrm{A}_{4}$ & $\begin{array}{l}\text { Max. liner temperature } \mathrm{T} \\
\text { Fuel mass flow } \mathrm{W}_{\mathrm{f}}\end{array}$ & Altitude relight capability \\
Outlet temperature $\mathrm{T}_{4}$ & & & \\
\hline
\end{tabular}

Table 1. Design input parameters

\begin{tabular}{|c|c|c|c|}
\hline Algorithm & Received parameters & Transferred parameters & $\begin{array}{l}\text { Directly coupled } \\
\text { algorithm(s) }\end{array}$ \\
\hline Flow distribution & $\begin{array}{l}\text { Combustor inlet } \\
\text { aerothermal parameters } \\
\text { (Table1.) }\end{array}$ & $\begin{array}{l}\text { 1)Zonal air data (dome, passage, } \\
\text { pilot and main stage, downstream } \\
\text { zone) 2)Component flow (swirling } \\
\text { air, fuel flow to pilot and main } \\
\text { injectors) 3) Cooling flow 4) } \\
\text { Zonal fuel-air ratios }\end{array}$ & $\begin{array}{l}\text { Combustor sizing, } \\
\text { emission, heat transfer } \\
\text { and cooling, } \\
\text { optimisation }\end{array}$ \\
\hline Combustor Sizing & $\begin{array}{l}\text { 1) Design input } \\
\text { parameter (Table1.) } \\
\text { 2) Zonal air data, } \\
\text { component flow data, } \\
\text { and cooling data (Flow } \\
\text { distribution) }\end{array}$ & $\begin{array}{l}\text { 1)Chamber and zonal dimensions, } \\
\text { 2)diffuser geometric data, 3)fuel- } \\
\text { air mixer geometric data, 4)cooling } \\
\text { system geometric data }\end{array}$ & $\begin{array}{l}\text { Flow distribution, } \\
\text { emission, heat transfer } \\
\text { and cooling, } \\
\text { performance, } \\
\text { optimisation }\end{array}$ \\
\hline Emission & $\begin{array}{l}\text { 1)Design input } \\
\text { parameters(Table1.) } \\
\text { 2)Zonal air and fuel } \\
\text { flow, fuel-air ratios 3) } \\
\text { Chamber and zonal } \\
\text { dimensions }\end{array}$ & $\begin{array}{l}\text { 1)Zonal gas temperature, radiation } \\
\text { and convection 2) Emission index }\end{array}$ & $\begin{array}{l}\text { Flow distribution, } \\
\text { combustor sizing, Heat } \\
\text { transfer and cooling, } \\
\text { optimisation }\end{array}$ \\
\hline $\begin{array}{l}\text { Heat transfer and } \\
\text { cooling }\end{array}$ & $\begin{array}{l}\text { 1)Design input } \\
\text { parameters (Table1.) } \\
\text { 2)Cooling system } \\
\text { geometric data 3) Zonal } \\
\text { gas temperature and } \\
\text { radiation }\end{array}$ & $\begin{array}{l}\text { 1) New cooling geometry data } \\
\text { 2)Liner temperature }\end{array}$ & $\begin{array}{l}\text { Flow distribution, } \\
\text { combustor sizing, } \\
\text { emission, optimisation }\end{array}$ \\
\hline Performance & $\begin{array}{l}\text { 1) Design input } \\
\text { parameters( Table1.) 2) } \\
\text { Engine data 3) Chamber } \\
\text { dimensions }\end{array}$ & $\begin{array}{l}\text { 1)Combustion efficiencies at } \\
\text { different engine operating points }\end{array}$ & Optimisation \\
\hline Optimisation & $\begin{array}{l}\text { 1)Design input } \\
\text { parameters (Table 1.) }\end{array}$ & $\begin{array}{l}\text { 1) Optimised variables } \\
\text { 2) Optimised objectives }\end{array}$ & $\begin{array}{l}\text { Flow distribution, } \\
\text { combustor sizing, } \\
\text { emission, heat transfer } \\
\text { and cooling, } \\
\text { performance }\end{array}$ \\
\hline
\end{tabular}

Table 2. Design interaction and coupling 


\begin{tabular}{|c|c|c|c|}
\hline Input parameters & Design variables & Design criteria & Output parameters \\
\hline $\begin{array}{l}\text { Combustor inlet } \\
\text { aerothermal parameters } \\
P_{3}, T_{3}, W_{3}, L H V, W_{f}, T_{4}\end{array}$ & $\begin{array}{l}\phi_{d}, \mu_{a \_p}, \mu_{a \_m}, \\
\mu_{f_{-} p}, \mu_{f_{-} m}\end{array}$ & $\begin{array}{l}\text { Emission, liner } \\
\text { temperature at DP } \\
\phi_{p_{-} d p} \text { and } \phi_{m_{-} d p} \text { are } \\
\text { similar at DP; } \\
\phi_{p_{-} i d l e} \text { close to } \\
\text { stoichiometric value }\end{array}$ & $\begin{array}{l}\text { Air mass flow at the pilot } \\
\text { and main, dome and } \\
\text { passage, downstream } \\
\text { zone. } \\
\text { Fuel flow at the pilot and } \\
\text { main stages } \\
\text { Fuel air ratio at the pilot, } \\
\text { and main, dome, } \\
\text { downstream zone }\end{array}$ \\
\hline
\end{tabular}

Table 3. Flow distribution design parameters summary

\begin{tabular}{|c|c|c|c|c|}
\hline Sizing & Input parameters & $\begin{array}{l}\text { Design } \\
\text { variables }\end{array}$ & Design criteria & $\begin{array}{l}\text { Output } \\
\text { parameters }\end{array}$ \\
\hline Chamber & $\begin{array}{l}\text { Design input } \\
\text { parameters (Table 1.) } \\
\text {; Dome, passage and } \\
\text { zonal mass flow }\end{array}$ & $\begin{array}{l}M a_{d}, M a_{p}, R_{\text {pit }} \\
R_{\text {pit_dz }}\end{array}$ & $\begin{array}{l}\text { Geometric } \\
\text { constraints } \\
\left(H_{c m}, L_{a m}\right) ; \\
\text { Combustion } \\
\text { efficiencies; Same } \\
\text { liner inclined angle }\end{array}$ & $\begin{array}{l}\text { Chamber, } \\
\text { passage, and } \\
\text { casing } \\
\text { dimensions (area, } \\
\text { height, length } \\
\text { and volume) }\end{array}$ \\
\hline Diffuser & $\begin{array}{l}\text { Combustor inlet } \\
\text { aerothermal } \\
\text { parameter, inlet } \\
\text { height, pitch and } \\
\text { flow area (Table1.) } \\
\text { Outlet flow Mach } \\
\text { number }\end{array}$ & $\mathrm{AR}, D_{d}$ & $\begin{array}{l}\text { Maximum permitted } \\
\text { LH, } \theta \text {; } \\
\text { Minimum cold loss; } \\
\text { Required outlet } \\
\text { Mach number, M32 }\end{array}$ & $\begin{array}{l}\text { Pre-diffuser area, } \\
\text { angle, length, } \\
\text { dump diffuser } \\
\text { area, dump gap }\end{array}$ \\
\hline $\begin{array}{l}\text { Fuel-air } \\
\text { mixer }\end{array}$ & $\begin{array}{l}\text { Fuel data (mass flow, } \\
\text { type and properties, } \\
\text { fuel pressure drop), } \\
\text { swirling flow data } \\
\text { (mass flow, pressure } \\
\text { drop) }\end{array}$ & $\begin{array}{l}D_{o}, \frac{D_{S}}{D_{0}}, \frac{A_{P}}{D_{S} D_{o}}, \\
\text { Vane type, and } \\
\text { angle }\end{array}$ & $\begin{array}{l}\text { Spray cone angle, } \\
\text { SMD, Ignition delay, } \\
\text { Dome geometric } \\
\text { constraint, SN }\end{array}$ & $\begin{array}{l}\text { Pressure atomiser } \\
\text { geometry, } \\
\text { premixing } \\
\text { chamber } \\
\text { geometry, swiler } \\
\text { geometry }\end{array}$ \\
\hline $\begin{array}{l}\text { Cooling } \\
\text { system }\end{array}$ & $\begin{array}{l}\text { Coolant mass, heat } \\
\text { transfer data } \\
\text { (radiation, } \\
\text { conduction, and } \\
\text { convention) }\end{array}$ & $N_{c r}, \mathrm{~S}, X_{D}, H_{S}$ & $\begin{array}{l}\text { Hole manufacturing } \\
\text { limit, same no. of } \\
\text { impingement and } \\
\text { effusion holes; Liner } \\
\text { temperature limit }\end{array}$ & $\begin{array}{l}\text { Cooling hole and } \\
\text { liner wall } \\
\text { geometry }\end{array}$ \\
\hline
\end{tabular}

Table 4. Combustor sizing design parameters summary 


\begin{tabular}{|c|c|c|c|}
\hline Inlet parameters & CFM56-5SAC & Genx-TAPS & E3-DAC \\
\hline Condition (-) & Take-off & Take-off & Take-off \\
\hline Total pressure $\mathrm{P}_{3}$ (atm) & $28.4 \quad(28.5[24])$ & $44.7(44.7[24][25])$ & $29.7[22]$ \\
\hline Total temperature $\mathrm{T}_{3}(\mathrm{~K})$ & $807.5 \quad(-)$ & $923.0 \quad(-)$ & $814.0[22]$ \\
\hline Air mass flow $\mathrm{W}_{3}(\mathrm{~kg} / \mathrm{s})$ & $47.6 \quad(-)$ & $94.9 \quad(-)$ & $55.2[22]$ \\
\hline Fuel mass flow $W_{\mathrm{f}}(\mathrm{kg} / \mathrm{s})$ & $(1.2[23])$ & $2.6(2.5[26])$ & $1.3[22]$ \\
\hline
\end{tabular}

Table 5. Design-point inlet parameters

\begin{tabular}{|c|c|c|c|c|c|c|c|c|c|}
\hline & \multicolumn{3}{|c|}{ CFM56-SAC } & \multicolumn{3}{|c|}{ GEnx-TAPS } & \multicolumn{3}{|c|}{ E3-DAC } \\
\hline Parameter & Data & $\begin{array}{l}\text { Calculat } \\
\text { ed } \\
\text { Data }\end{array}$ & $\begin{array}{l}\text { Difference } \\
(\%)\end{array}$ & Data & $\begin{array}{l}\text { Calculated } \\
\text { data }\end{array}$ & $\begin{array}{l}\text { Difference } \\
(\%)\end{array}$ & Data & $\begin{array}{l}\text { Calcula } \\
\text { ted data }\end{array}$ & $\begin{array}{l}\text { Difference } \\
(\%)\end{array}$ \\
\hline $\begin{array}{l}\text { Dome flow } \\
\text { fraction (-) }\end{array}$ & $0.25[3]$ & 0.26 & 4 & $0.70[3]$ & 0.66 & 6.1 & $0.66[22]$ & 0.63 & 4.5 \\
\hline $\begin{array}{l}\text { Passage flow } \\
\text { fraction (-) }\end{array}$ & $0.75[3]$ & 0.74 & 1.3 & $0.30[3]$ & 0.34 & 13.3 & $0.34[22]$ & 0.37 & 8.8 \\
\hline $\begin{array}{l}\text { Diffuser length } \\
(\mathrm{m})\end{array}$ & $0.119[23]$ & 0.111 & 6.7 & $0.114^{*}$ & 0.109 & 4.4 & $0.069[22]$ & 0.085 & 23.2 \\
\hline Damp gap (m) & $0.040 *$ & 0.042 & 4.7 & $0.073 *$ & 0.061 & 16.4 & $0.042 *$ & 0.048 & 12.5 \\
\hline Dome height (m) & 0.086 [23] & 0.080 & 3.3 & $0.134 *$ & 0.130 & 3.0 & $0.123^{*}$ & 0.122 & 0.8 \\
\hline $\begin{array}{l}\text { Casing height } \\
\text { (m) }\end{array}$ & $0.120[23]$ & 0.134 & 10.4 & $0.174 *$ & 0.160 & 8.1 & $0.157^{*}$ & 0.142 & 9.6 \\
\hline Liner length (m) & $0.178[23]$ & 0.162 & 9.0 & $0.157 *$ & 0.146 & 7.0 & $0.160 *$ & 0.153 & 4.4 \\
\hline No. of injector - & $20[23]$ & 20 & 0 & $22[3]$ & 22 & 0 & 30 [19] & 30 & 0 \\
\hline
\end{tabular}

Table 6. Flow distribution, combustor dimension and fuel injector data comparisons

\begin{tabular}{c|ccccc}
\hline $\begin{array}{c}\text { Test } \\
\text { condition }\end{array}$ & $\begin{array}{c}\text { Inlet } \\
\text { pressure } \\
(\mathbf{a t m})\end{array}$ & $\begin{array}{c}\text { Inlet temperature } \\
(\mathbf{K})\end{array}$ & $\begin{array}{c}\text { Mass } \\
\text { flow } \\
(\mathbf{k g} / \mathbf{s})\end{array}$ & $\begin{array}{c}\text { Measured top } \\
\text { liner wall } \\
\text { temperature } \\
(\mathbf{K})\end{array}$ & $\begin{array}{c}\text { Calculated wall } \\
\text { temperature } \\
(\mathbf{K})\end{array}$ \\
\hline 1 & 10 & 589 & 6.05 & 690 & 758 \\
2 & 20 & 589 & 12.10 & 706 & 770 \\
3 & 26.7 & 589 & 16.16 & 770 & 812 \\
4 & 10 & 756 & 6.05 & 861 & 902 \\
5 & 10 & 922 & 6.05 & 1061 & 1098 \\
\hline
\end{tabular}

Table 7. Measured liner temperature vs predicted liner temperature at different powers

\begin{tabular}{c|ccccc}
\hline $\begin{array}{c}\text { Test } \\
\text { condition }\end{array}$ & $\begin{array}{c}\text { Inlet } \\
\text { pressure } \\
(\mathbf{a t m})\end{array}$ & $\begin{array}{c}\text { Inlet } \\
\text { temperature } \\
(\mathbf{K})\end{array}$ & $\begin{array}{c}\text { Equivalence } \\
\text { ratio } \\
(-)\end{array}$ & $\begin{array}{c}\text { Measured } \\
\text { gas } \\
\text { temperature } \\
(\mathbf{K})\end{array}$ & $\begin{array}{c}\text { Calculated } \\
\text { gas } \\
\text { temperature } \\
(\mathbf{K})\end{array}$ \\
\hline 1 & 10 & 589 & 1.0 & 2180 & 2460 \\
2 & 20 & 589 & 1.0 & 2190 & 2480 \\
3 & 26.7 & 589 & 1.0 & 2256 & 2488 \\
\hline
\end{tabular}

Table 8 . Comparisons between measured and calculated gas temperature 


\begin{tabular}{l|c|l|c}
\hline \multicolumn{2}{c|}{ Pure Effusion Cooling } & \multicolumn{2}{c}{ Combined Cooling (Impingement + Effusion) } \\
\hline Liner segmental length (m) & 0.02 & Liner segmental length $(\mathrm{m})$ & 0.02 \\
liner thickness $(\mathrm{m})$ & 0.001 & Liner thickness $(\mathrm{m})$ & 0.001 \\
Hole diameter (m) & 0.001 & Double liner thickness $(\mathrm{m})$ & 0.001 \\
Coolant mass flow (kg/s) & 0.4 & Effusion hole diameter $(\mathrm{m})$ & 0.001 \\
Gas temperature (k) & 1996.6 & Coolant mass flow $(\mathrm{kg} / \mathrm{s})$ & 0.4 \\
Hole angle (degree) & 20 & Gas temperature (k) & 1996.6 \\
Hole spacing to diameter & 3 & Effusion hole angle (degree) & 20 \\
& & Impingement hole diameter (m) & 0.001 \\
& & Effusion hole spacing to diameter & 3 \\
& & Impingement hole spacing to & 3 \\
& & diameter & 0.002 \\
\hline
\end{tabular}

Table 9. Geometric and input parameters for two cooling technologies

\begin{tabular}{l|c|c}
\hline \multicolumn{1}{c|}{ Parameters } & CFM56-SAC & Genx-TAPS \\
\hline Altitude $(\mathrm{m})$ & $10668[21]$ & $12000[21]$ \\
Combustor volume $\left(\mathrm{m}^{3}\right)$ & 0.028 & 0.036 \\
Windmilling pressure $(\mathrm{kpa})$ & 31.6 & 53.6 \\
Windmilling temperature $(\mathrm{K})$ & 254.6 & 296.9 \\
Windmilling mass flow $(\mathrm{kg} / \mathrm{s})$ & 0.55 & 1.8 \\
Altitude relight combustion efficiency & $82.5(80[10][14])$ & $83.0(80[10][14])$ \\
Combustion efficiency at DP $(\%)$ & 99.7 & 99.7 \\
& $(99.9[10][18][24][25])$ & $(99.9[10][18][24][25])$ \\
\hline
\end{tabular}

Table 10. Performance prediction at altitude relight and design point

\begin{tabular}{l|c}
\hline \multicolumn{1}{c|}{ Parameters } & Value \\
\hline Design point condition & Take-off \\
Total inlet pressure $(\mathrm{atm})$ & 23.0 \\
Total inlet temperature $(\mathrm{k})$ & 810 \\
Air mass flow $(\mathrm{kg} / \mathrm{s})$ & 24.0 \\
Fuel mass flow $(\mathrm{kg} / \mathrm{s})$ & 0.57 \\
Combustion efficiency $(\%)$ & 99 \\
Liner temperature $(\mathrm{K})$ & $<1123 \mathrm{~K}$ \\
EINO $_{\mathrm{x}}(\mathrm{g} / \mathrm{kg})$ & 6 \\
\hline
\end{tabular}

Table 11. Combustor inlet parameters and design targets at DP condition 


\begin{tabular}{l|l}
\hline Parameter & Results \\
\hline Dome air fraction (DP) & 0.64 \\
Passage air fraction(DP) & 0.36 \\
Dome cooling fraction (DP) & 0.128 \\
Pilot air fraction (DP) & 0.12 \\
Main air fraction (DP) & 0.52 \\
Pilot fuel fraction (DP) & 0.185 \\
Main fuel fraction (DP) & 0.815 \\
Pilot zone equivalence ratio (DP) & 0.55 \\
Main zone equivalence ratio (DP) & 0.55 \\
Pilot fuel fraction (Idle) & 1 \\
Main fuel fraction (Idle) & 0 \\
Pilot zone equivalence ratio (Idle) & 1.20 \\
Main zone equivalence ratio (Idle) & 0 \\
Pilot fuel fraction (Approach) & 1 \\
Main fuel fraction (Approach) & 0 \\
Pilot zone equivalence ratio (Approach) & 1.5 \\
Main zone equivalence ratio (Approach) & 0 \\
Pilot fuel fraction (Mid-cruise) & 0.22 \\
Main fuel fraction (Mid-cruise) & 0.78 \\
Pilot zone equivalence ratio (Mid-cruise) & 0.54 \\
Main zone equivalence ratio (Mid-cruise) & 0.54 \\
Pilot fuel fraction (Cruise) & 0.185 \\
Main fuel fraction (Cruise) & 0.815 \\
Pilot zone equivalence ratio (Cruise) & 0.52 \\
Main zone equivalence ratio (Cruise) & 0.52 \\
Pilot fuel fraction (Climb) & 0.185 \\
Main fuel fraction (Climb) & 0.815 \\
Pilot zone equivalence ratio (Climb) & 0.50 \\
Main zone equivalence ratio (Climb) & 0.50 \\
\hline
\end{tabular}

Table 12. Air and fuel split results

\begin{tabular}{cc}
\hline Mission & Peak temperature $(\mathbf{K})$ \\
\hline Taxi & 534.6 \\
Approach & 981.8 \\
Cruise & 808.1 \\
Mid-cruise & 702.3 \\
Climb & 1006.4 \\
Take-off & 1060.4 \\
\hline Liner material & Haynes 188 \\
\hline
\end{tabular}

Table 13. Liner wall peak temperature at different engine thrust conditions 


\begin{tabular}{l|l}
\hline Engine thrust & Combustion efficiency (\%) \\
\hline Altitude relight & 84.0 \\
Idle & 99.1 \\
Approach & 99.3 \\
Cruise & 99.5 \\
Mid-Cruise & 99.2 \\
Climb & 99.6 \\
Take-off & 99.7 \\
\hline
\end{tabular}

Table 14. Performance evaluation for the designed combustor

\begin{tabular}{|c|c|c|c|c|c|c|c|c|c|c|c|}
\hline Variable & $L_{p d}$ & $H_{d}$ & $H_{p}$ & $\boldsymbol{H}_{c}$ & $L_{l}$ & $V_{l}$ & $\Delta \boldsymbol{P}_{d} / \boldsymbol{P}_{3}$ & $\Delta \boldsymbol{P}_{l} / \boldsymbol{P}_{3}$ & $\eta_{a r}$ & $E \boldsymbol{I}_{\text {Nox }}$ & $T_{\max }$ \\
\hline$V_{p}{ }^{1}$ & - & - & $\bullet$ & $\bullet$ & $*$ & - & - & - & - & - & $\bullet$ \\
\hline$\phi_{d}^{2}$ & * & • & • & • & $*$ & - & $*$ & - & - & $\bullet$ & $\bullet$ \\
\hline$D_{d} / H^{3}$ & • & - & - & - & - & - & $\bullet$ & * & - & - & - \\
\hline$a^{4}$ & • & - & - & - & • & • & • & $*$ & $*$ & $\bullet$ & $\bullet$ \\
\hline$b^{5}$ & $\bullet$ & - & - & - & $\bullet$ & $\bullet$ & $*$ & - & $*$ & $*$ & $*$ \\
\hline$c^{6}$ & $\bullet$ & - & - & - & $\bullet$ & $\bullet$ & * & - & $*$ & * & * \\
\hline$\tau_{f} / \tau_{r}{ }^{7}$ & - & - & - & - & - & - & - & - & - & - & - \\
\hline$\tau_{d} / \tau_{r}^{\mathbf{8}}$ & - & - & - & - & - & - & - & - & - & - & - \\
\hline$X_{D}{ }^{9}$ & - & - & - & - & - & - & - & - & - & - & $\bullet$ \\
\hline & - & - & - & - & - & - & - & - & - & - & • \\
\hline
\end{tabular}

NB: - below $1 \% * 1 \%-5 \% \bullet 5 \%-10 \%$ • above $10 \%$ 1: $25-45 \mathrm{~m} / \mathrm{s} \quad$ 2: $0.5-0.6$ 3: $1.5-3.0$ 4:1.6-2.0 5: $0.00125-$ 0.00165 6:380-420 7:0.5-2.0 8:0.5-2.0 9:0.5-0.9 10:0.001-0.004m

Table 15. Sensitivity analysis - impact of assumed variables on design outcomes 


\title{
Development and application of a preliminary design methodology for modern low emissions aero combustors
}

\author{
Liu, Yize
}

SAGE

Liu Y, Sun X, Sethi V, et al., (2021) Development and application of a preliminary design methodology for modern low emissions aero combustors, Proceedings of the Institution of Mechanical Engineers, Part A: Journal of Power and Energy, Volume 235, Issue 4, June 2021, pp. 783-806

https://doi.org/10.1177/0957650920919549

Downloaded from Cranfield Library Services E-Repository 